\author{
ياسخ ارقام گندم ايرانى به افزايش غلظت دىاكسيد كربن هوا و تنش شورى \\ مهران صالح'، مرتضى زاهدى ب*و حميدرضا عشقىزاده

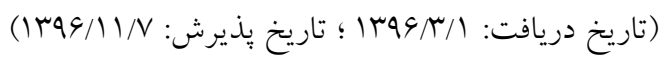

جִكيده

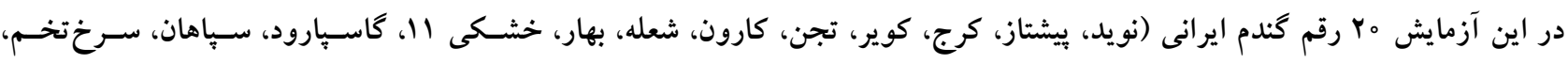

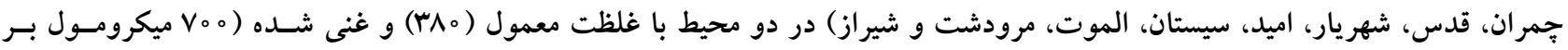

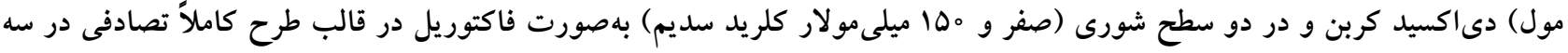

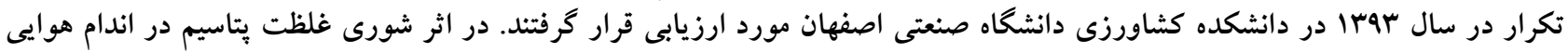

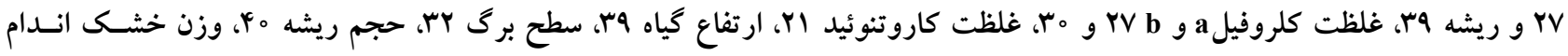

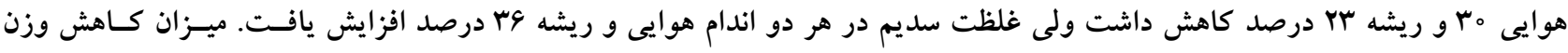

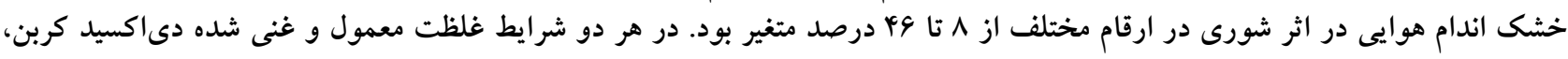

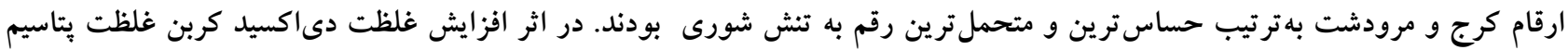

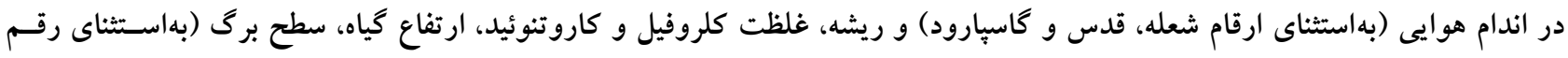

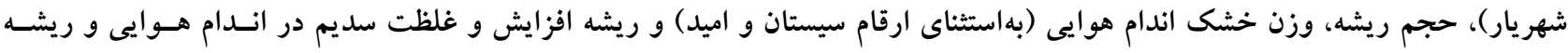

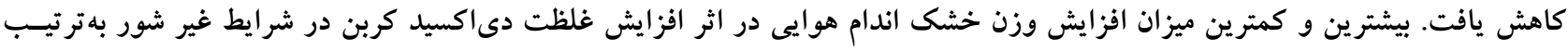

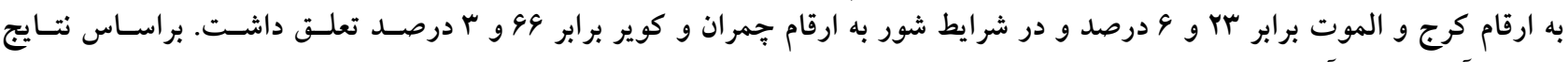

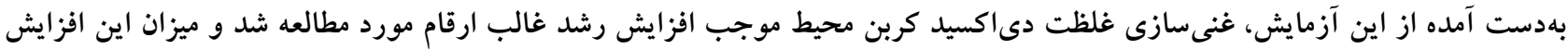

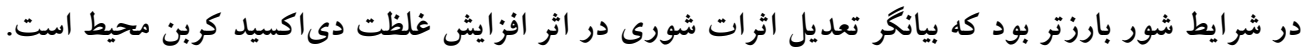

وازههاى كليدى: تغيير اقليم، ارقام گندم، غلظت دىاكسيد كربن محيط، شورى

ا، r و r.، بهترتيب دانشآموخته كارشناسى ارشد، دانشيار و استاديار، كروه زراعت و اصلاح نباتات، دانشكده كشاورزى، دانشخاه صنعتى اصفهان

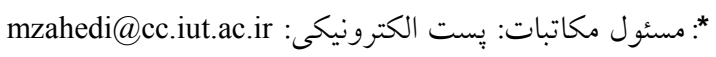


ماده خشك بيشترى تقسيم شده و غلظـت آن كـاهش مسىيابـــ

مقدمه

تنش شورى از جمله عوامل محيطى عمــده محسدود كنـــهـ

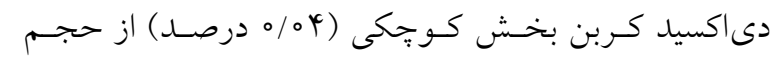

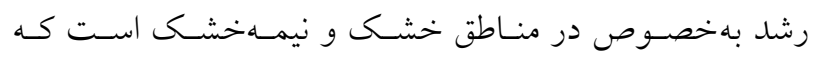

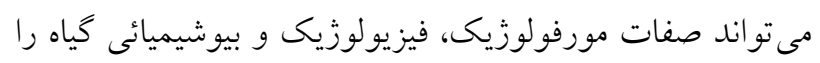

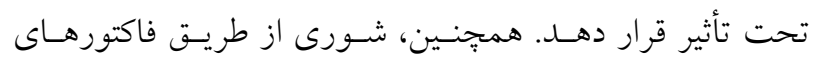

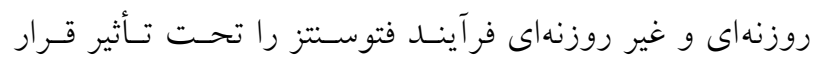

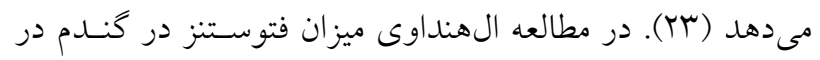
اثر تنش شورى حدود 90 درصد كاهش يافت (11). در مطالعسه

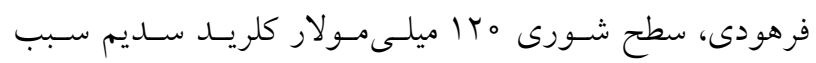

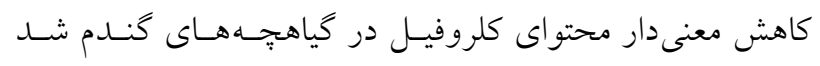

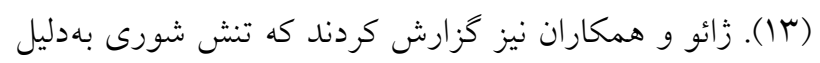
افزايش غلظت سديم در برك، سبب كاهش كلروفيل و فتوسـتنز

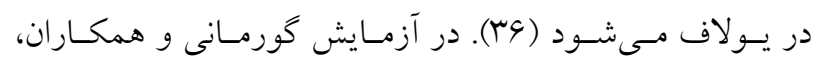

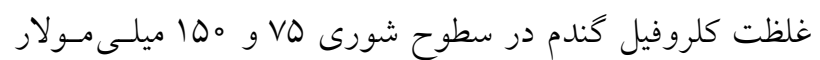

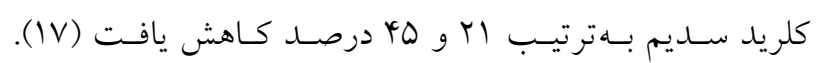
تخريب كلروفيل بهوسيله اكسيزن فعال يكى از مهمترين دلايسل

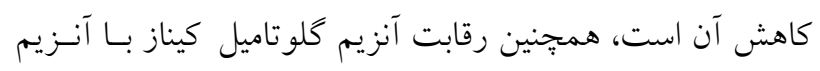

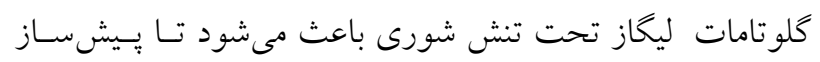

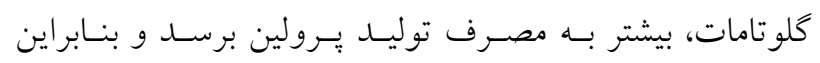

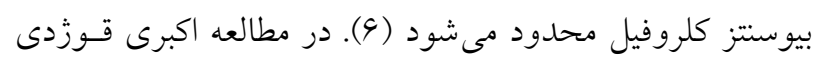

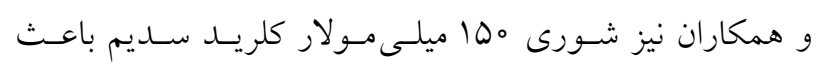

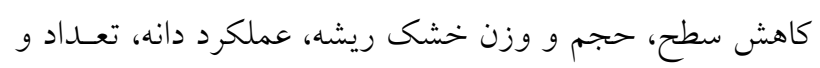

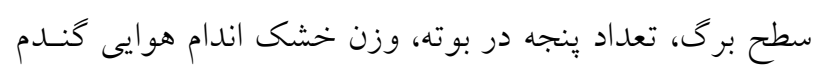

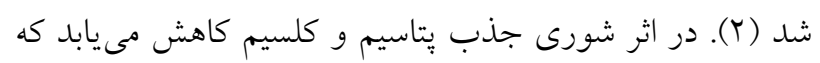

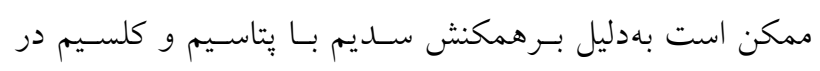

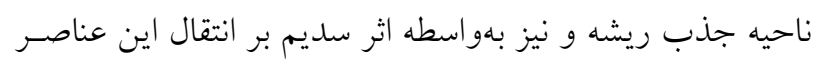

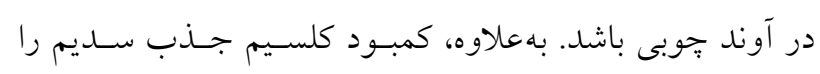

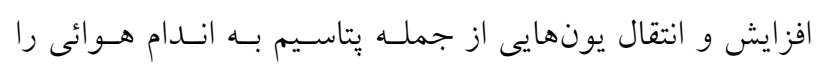

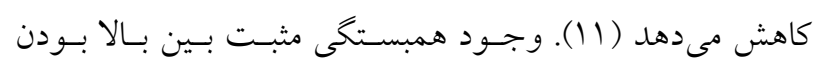

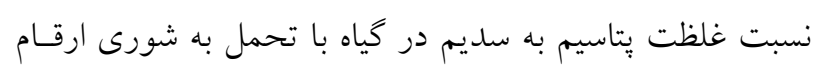

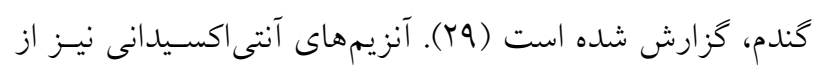

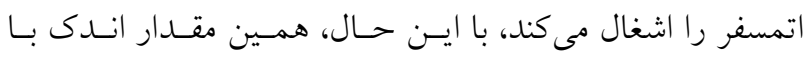

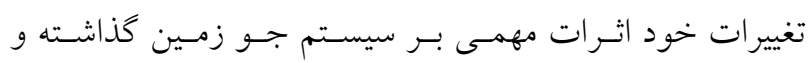

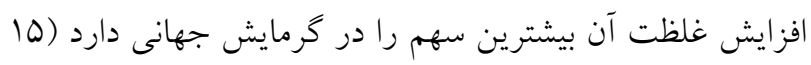

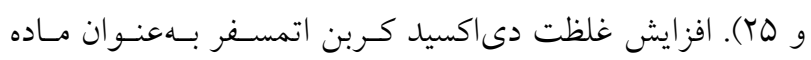

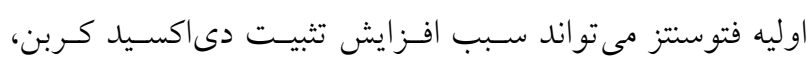
سطح برى و زيست توده كياه شود. دليل اصلى افزايش فتوستستز

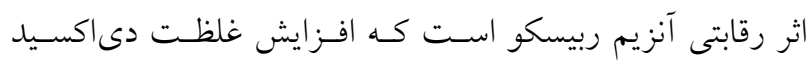

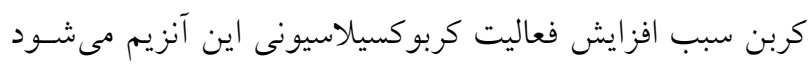

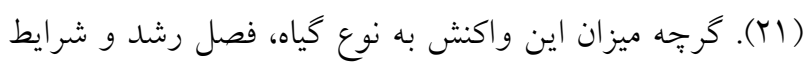

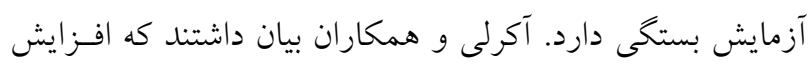

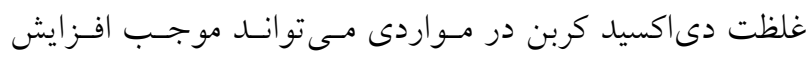

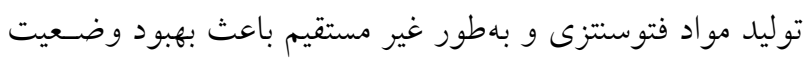

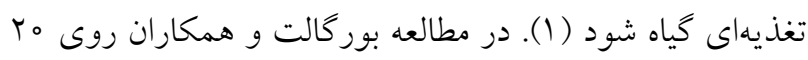

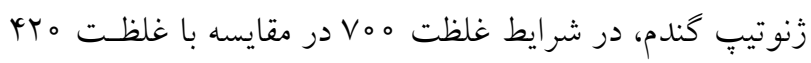

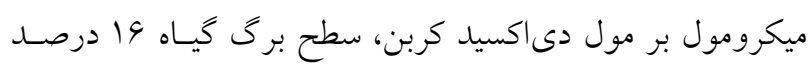

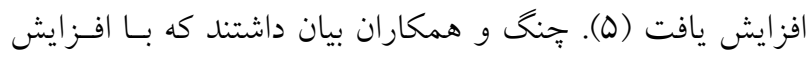

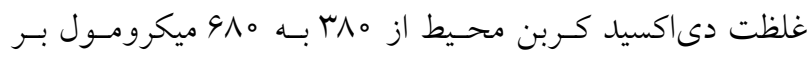

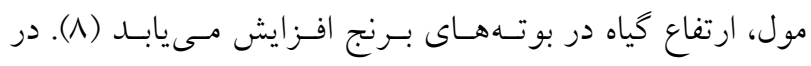

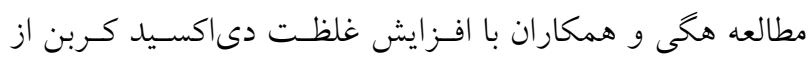

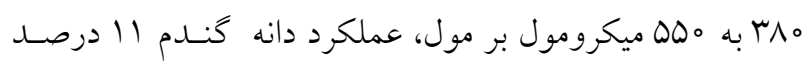

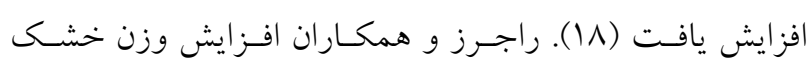

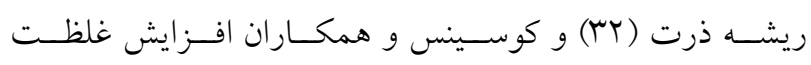

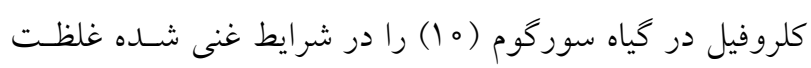

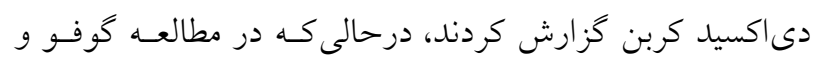

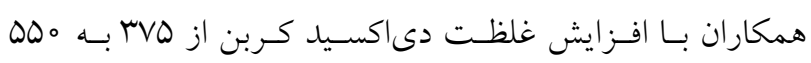

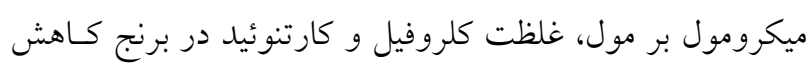

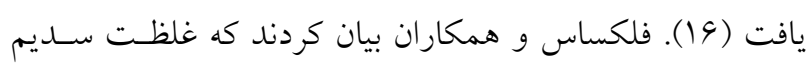

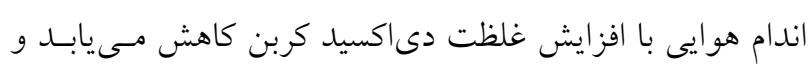

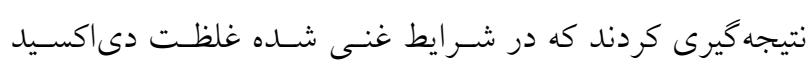

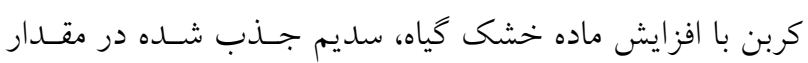


جمله مؤثرترين سيستم دفاعى در مقابله با آسيبهـاى ناشسى از تكرار، ارزيابى شدند.

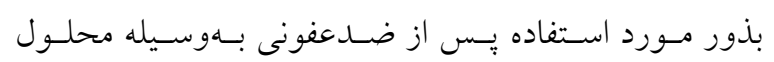

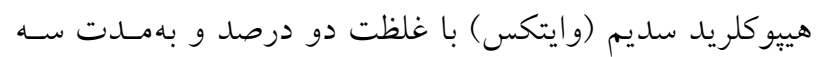

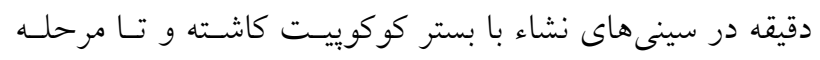

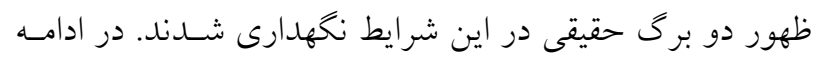

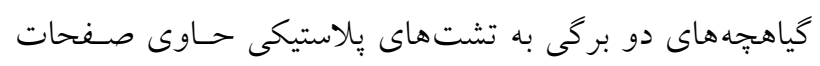

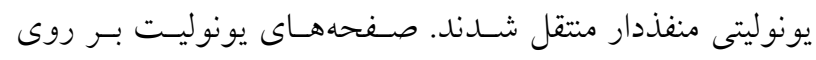

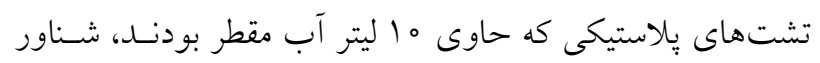

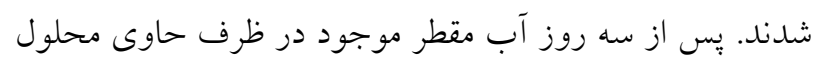
غذايى هو گلند جايخزين شــــ در طـول دوره آزمـايش اسـيديته

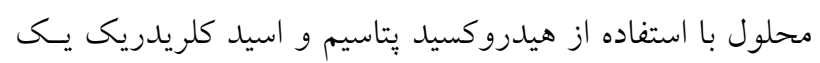
نرمال، در حدود ه/9 حفظ شد. قابليت هدايت الكتريكى (EC)

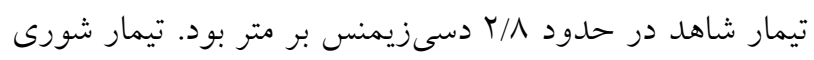

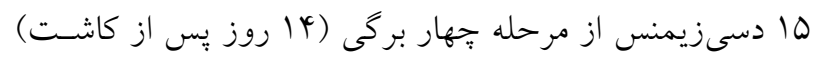
بهتدريج طى يك هفته اعمال شد.

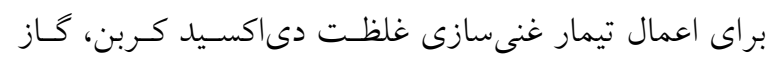

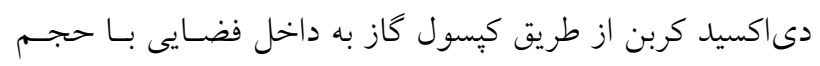

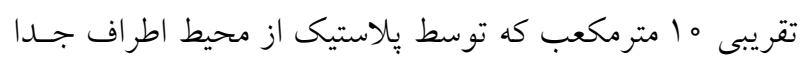

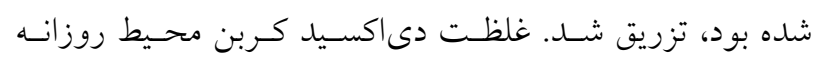

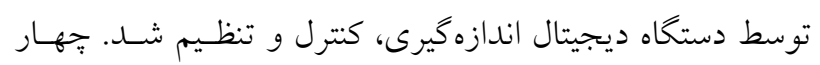
هفته پِ از اعمال تيمـار شـورى (شـروع ينجسهزنسى)، كياهـان

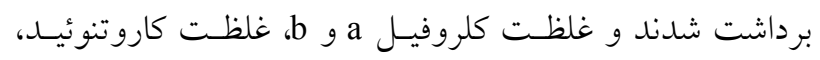

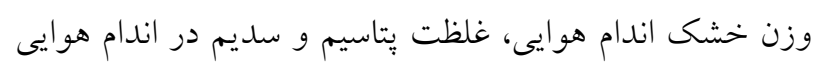
و ريشه اندازهيرى شد.

\section{نحوه اندازهيرى صفات}

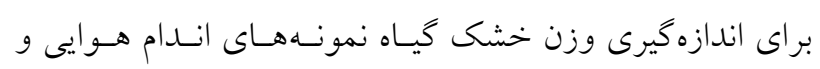

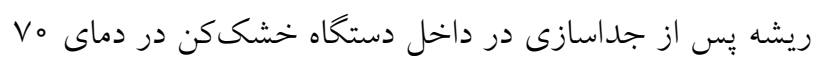

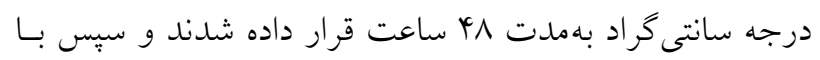

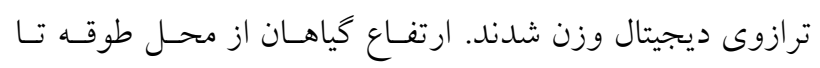

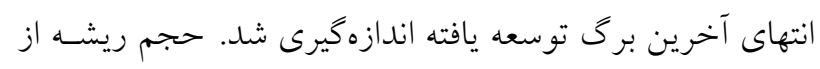

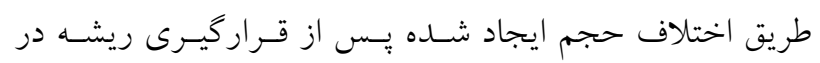

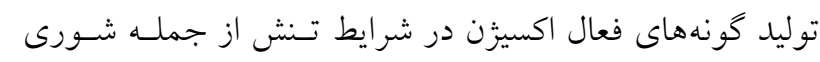

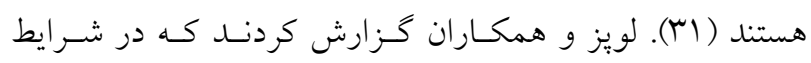

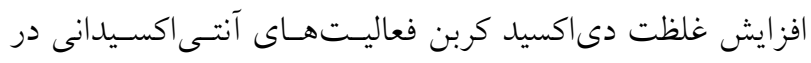

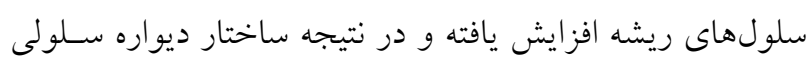

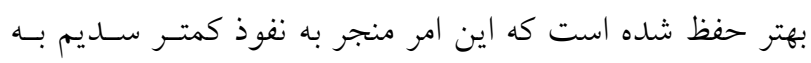

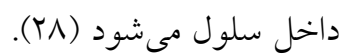
وجود برهمكنش بين غلظت دى اكسيد كربن، شورى و رقــم نيز گزارش شده است. جنانجه در آزمايش نيكلاس و همكـاران

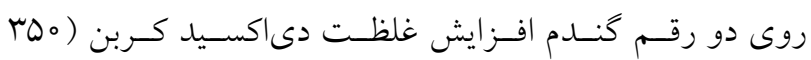

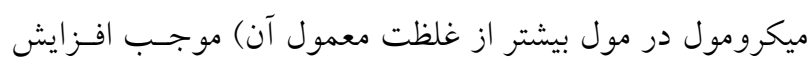

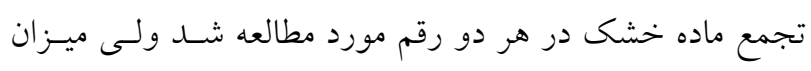

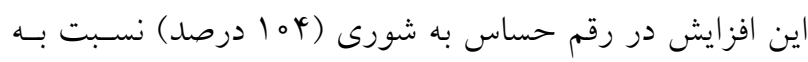

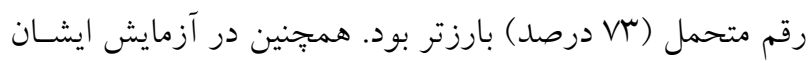
ميزان افزايش ماده خشك، سطح برى و ونجهلزنسى كيـاه در اثـر

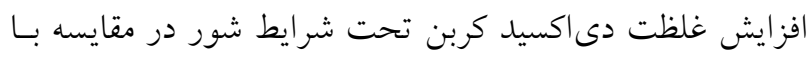

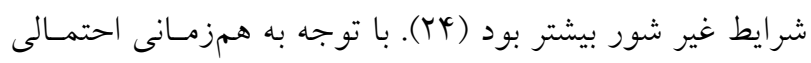

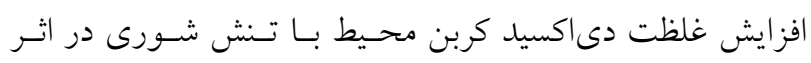

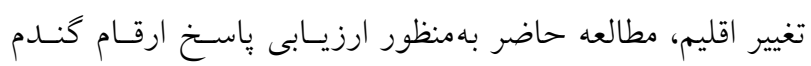

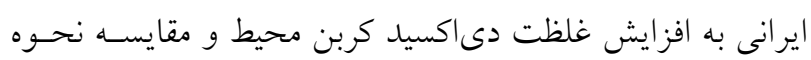
اين ياسخ در شرايط شور و غير شور انجام گرفت.

\section{مواد و روشها - - ماد}

اين تحقيق در كلخانه تحقيقـاتى دانشـكده كشـاورزى دانشـاه

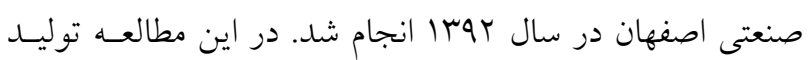

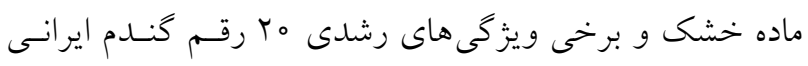

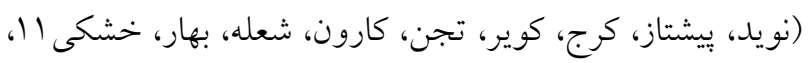

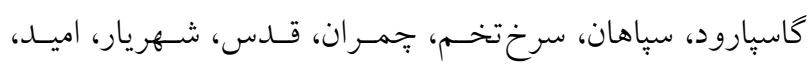

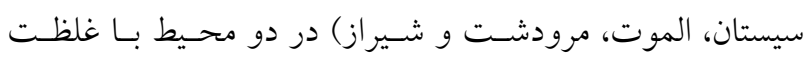

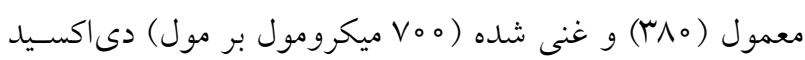

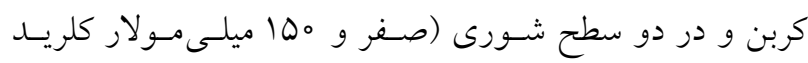

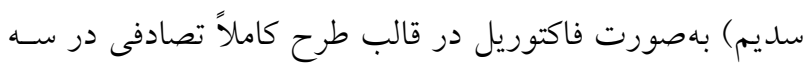


قابليت آنها را در ورود انتخابى يونها تغيير مىدهد (rاן). تأثير افزايش غلظت دىاكسيد كربن بر غلظت يتاسيم اندام هوايى، غلظت سديم ريشه و نسبت يتاسيم به سديم اندام هوايى و ريشه در سطح احتمال يك درصد و بر غلظت سديم اندام هوايى و غلظت يتاسيم ريشه در سطح احتمال ينج درصد معنىدار بود (جدول ()). در اثر افزايش غلظت دىاكسيد كربن

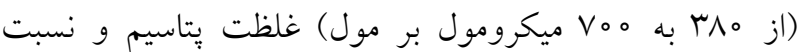

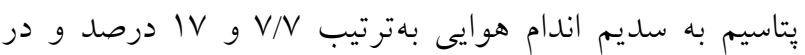

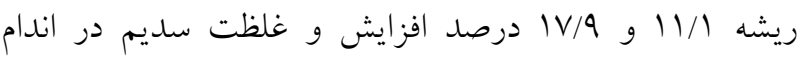
هوايى و ريشه N و V/a درصد كاهش يافت (جدول Y). اين

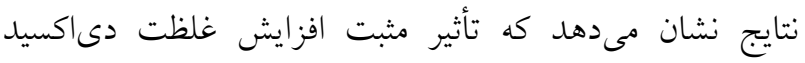
كربن بر غلظت يّاسيم ريشه نسبت به اندام هوايى بارزتر بوده،

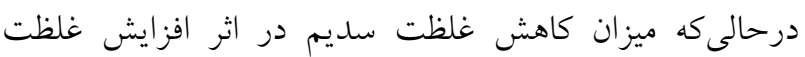
دى اكسيد كربن در اندام هوايى و ريشه مشابه بود. در شرايط

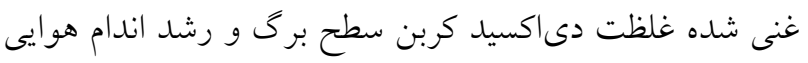
افزايش مى يابد و در جنين شر ايطى با افزايش ماده خشك كياه، سديم جذب شده در مقدار بيشترى از ماده خشك بِخش شده و در نتيجه غلظت آن كاهش مى يابد (YY). در مطالعه زهتاب نيز غلظت يتاسيم در اندام هوايى و ريشه جو در شرايط غلظت غنى شده دىاكسيد كربن بهترتيب V/ ا و و V/D درصد افزايش

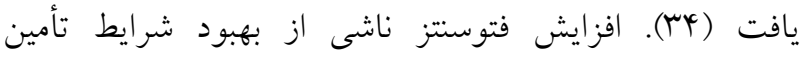

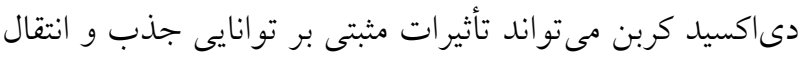
يتاسيم و جلوگيرى از جذب سديم توسط ريشه و انتقال آن از ريشه به اندام هوايى در شرايط تنش شورى داشته باشد (YY). لويز و همكاران، كزارش كردند كه در شرايط افزايش غلظت دىاكسيد كربن فعاليت آنتىاكسيدانى در سلولهاى ريشه افزايش مىيابد، در نتيجه ساختار ديواره سلولى بهتر حفظ شده

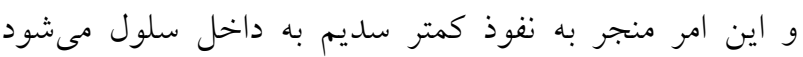

تفاوت ارقام مورد مطالعـه از نظـر غلظـت ســيم ريشـه و

غلظت بتاسيم و نسبت يتاسيم به سديم در اندام هوايى و ريشـه در سطح احتمال يك درصد و از نظر غلظت سديم اندام هو ايى بـ
حجـم مشخصسى از آب برحسب سـانتى متسر مكعـب در بوتسه

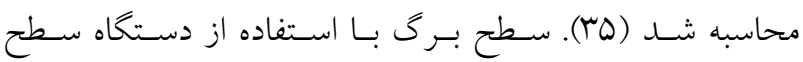
بركسنج الكترونيكى (Green Leaf Area Tester model GA-5)

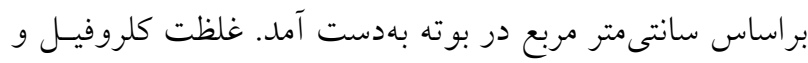

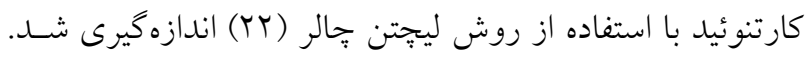
براى تعيين غلظت سديم و يتاسـيم (انـام هـوايى و ريشـهـ) در

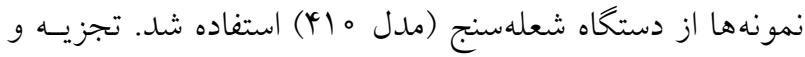
تحليل دادهها با استفاده از نرمافزار SAS و مقايسه ميانكَينها بـا استفاده از آزمون LSD در سطح احتمال ينج درصد با استفاده از

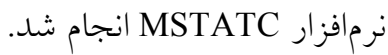

\section{نتايج و بحث} غلظت سديم و بتاسيم اندام هوايى و ريشه

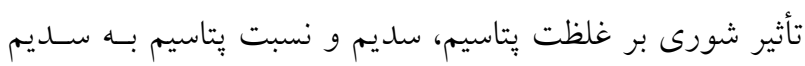

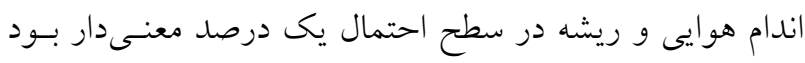

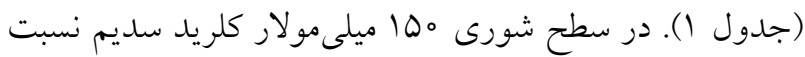
به تيمار غير شور غلظت بِّاسيم و نسبت بِّاسيم به سديم انـدام

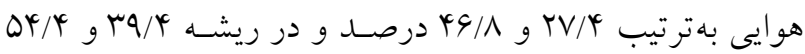
درصد كاهش و غلظت سديم اندام هوايى و ريشه درصـــ افـزايش يافـت (جـــول r). در مطالعـه اسـفنديارى و

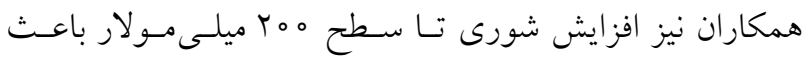

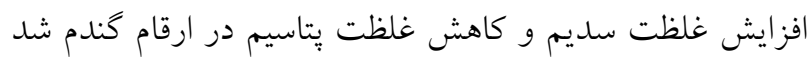

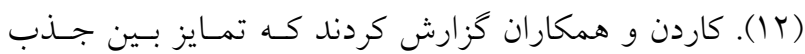

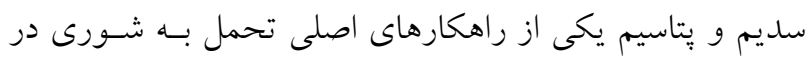

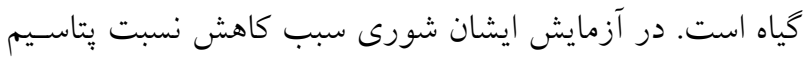

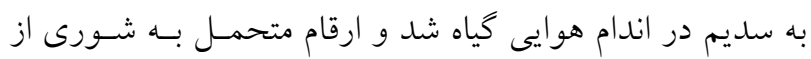

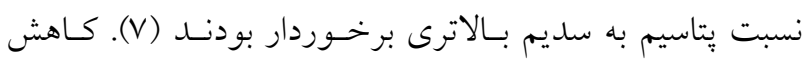

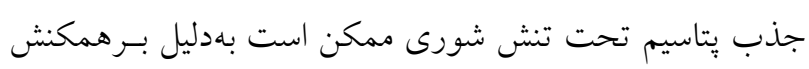
سديم با يتاسيم در ناحيه جذب ريشه و نيز اثر سديم بــر انتقـال

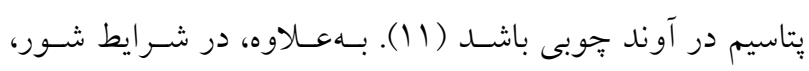
غلظت بالاى سديم باعث جلوكيرى از كاركرد يتاسيم در ريشـهـ

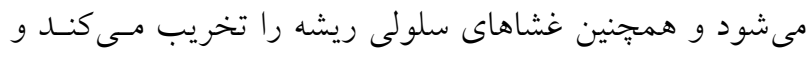




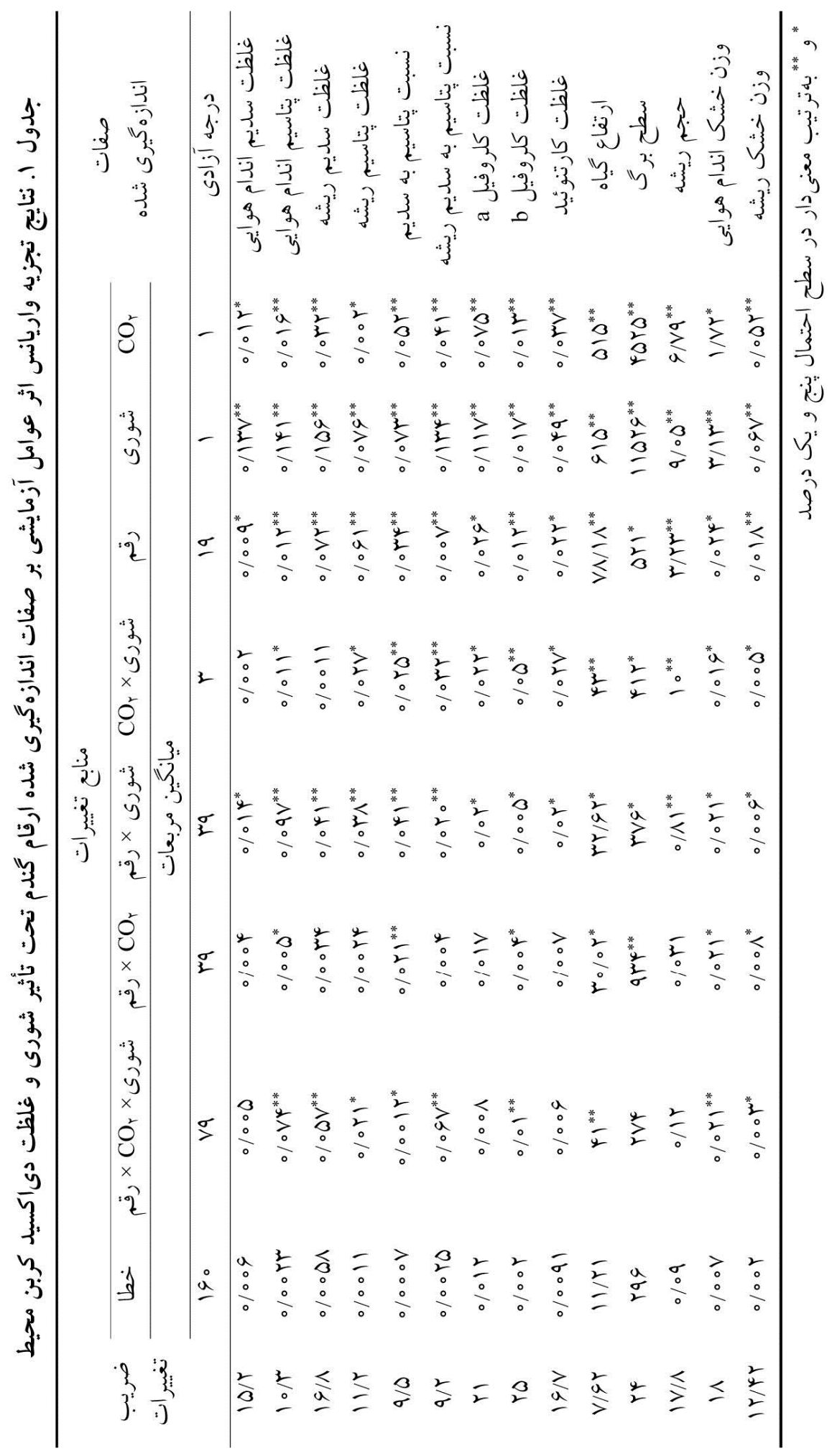


جدول r. مقايسه ميانگينهاى غلظت سديم و بتاسيم اندام هوايى و ريشه (ميلى مول بر گرم وزن خشك) و كلروفيل (ميلى گرم بر گرم وزن

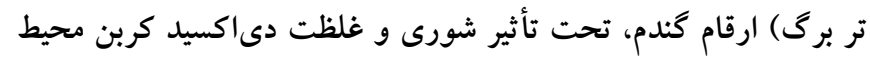

\begin{tabular}{|c|c|c|c|c|c|c|c|c|}
\hline كلروفيل b & a كلروفيل a & به سبت بـاسيم ريشه & سديم اندام هيت هو ايى به & ريشاسيم & سيشم & يتاسيم اندام & سديم اندام & عامل آزمايشى \\
\hline & & & & & & & & $\begin{array}{l}\text { سطح شورى ميلى مولار) } \\
\text { (مور }\end{array}$ \\
\hline o/ Mypa & $\circ / D \circ V^{a}$ & $1 / \Delta q^{a}$ & $1 / 49 a$ & $0 /$ Mrya & $\circ / Y I V^{b}$ & $\circ / T \wedge q^{a}$ & $\circ / 19 Y^{b}$ & صفر \\
\hline$\circ /|V|^{b}$ & $\circ M^{\prime} V^{b}$ & o/VYYcb & $\circ / N a Y^{b}$ & $\circ / Y^{\prime} \wedge^{b}$ & $\circ /$ rara & $\circ / T \circ \varphi b$ & $0 /\left.Y G\right|^{a}$ & 100 \\
\hline \multirow{4}{*}{$\begin{array}{l}\circ / / 9 \circ b \\
\circ / Y Y \triangleright^{a}\end{array}$} & & & & & & & & 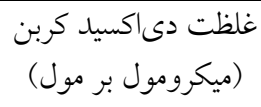 \\
\hline & $\circ / 41 \circ b$ & $1 / 0 \varphi^{b}$ & $1 / 0 \circ b$ & $0 /\left.T \&\right|^{b}$ & $\circ / T 4 \Delta^{\mathrm{a}}$ & $0 / \pi \mu \varphi_{b}$ & $0 / \pi r \varphi^{a}$ & $\mu_{\Lambda}$ \\
\hline & $0 /\left.49\right|^{a}$ & $1 / T \Delta^{a}$ & $1 / I V^{a}$ & $\circ / r q \circ a$ & O/Yykb & $0 / T \Delta r^{4 a}$ & $\circ / Y I V b$ & Voo \\
\hline & & & & & & & & رقم \\
\hline$\circ / 499 a^{a}$ & $\circ / \mathcal{A} V Y^{\mathrm{ab}}$ & $1 / \mathrm{V}^{\mathrm{b}}$ & $1 / \mu_{\circ} a$ & $\circ / N_{1} \circ \mathrm{ab}$ & o/YYQ ef & $\circ / Y V \wedge^{\mathrm{a}}$ & $0 / Y \mid Y^{\mathrm{cd}}$ & سباهان \\
\hline$\circ / 49 \wedge^{a}$ & $\circ / 4 \circ \circ f-h$ & $1 / \mu q^{a}$ & $1 / Y Y^{\mathrm{co}}$ & $\circ / M_{\Lambda}$ & $\circ /\left.Y \Delta\right|^{d-f}$ & $\circ / T V Q^{a}$ & $\circ / Y Y_{\circ} \mathrm{cd}$ & سيستان \\
\hline$\circ / 19 V^{g h}$ & $\circ / \mu q \circ g-i$ & $1 / T y d$ & $1 / \circ \wedge^{g}$ & $\circ / Y \wedge \wedge^{\mathrm{c}-\mathrm{e}}$ & $\circ / T \Delta r_{d-f}$ & $0 /$ Y \&qd-f & - Yrqqcd & نويد \\
\hline$\circ / I V Y^{i}$ & $\circ / 4 Y D^{e f}$ & $1 / r r^{e}$ & $1 / T \mu^{c}$ & $\circ / T \wedge I^{e}$ & $0 /$ Y 49 d-f & $\circ / Y \varphi \Delta^{\mathrm{a}-\mathrm{d}}$ & $\circ / T \backslash Q^{c d}$ & شعله \\
\hline$\circ / 1 Y c^{k}$ & o/frld-f & $\circ / 911^{m}$ & $\circ / \wedge ఎ \circ \mathrm{m}$ & $\circ / T \Delta Y^{g h}$ & $\circ / T V V^{a-c}$ & $\circ / Y \mid c^{h-j}$ & $\circ / T \Delta Y^{c a b}$ & سرختخم \\
\hline$\circ / Y \backslash \Delta^{\mathrm{d}-\mathrm{f}}$ & o/frryd-f & $1 / 19 \mathrm{~g}$ & $1 / 0 \varphi^{c_{i}}$ & $\circ / T \varphi_{\circ} \mathrm{f}-\mathrm{h}$ & $\circ / K r \Lambda^{f}$ & o/rTQg-i & $\circ / T \backslash Q^{c d}$ & بيشتاز \\
\hline$\circ / Y T D^{d e}$ & $\circ / Y^{q} V \circ^{a-c}$ & $1 / \mu Y^{c}$ & $1 / Y y^{c}$ & ०/ ra ${ }^{\mathrm{cd}}$ & $\circ / T r \Lambda^{f}$ & $\circ / Y \Delta \wedge^{\mathrm{b}-\mathrm{d}}$ & $\circ / Y \circ V^{d}$ & جمران \\
\hline$\circ / \Lambda \Lambda^{\mathrm{h}}$ & $\circ / 4 \mid r^{e-h}$ & $1 /\left.0\right|^{4}$ & $1 / \circ \gamma^{j}$ & $\circ / T \Delta V g h$ & $\circ / T \Delta Q^{b-f}$ & $\circ /$ YVgh & o/YYYcd & كرج \\
\hline$\circ / 1 \wedge^{k}$ & $\circ / \uparrow \wedge c^{a b}$ & $1 / 1 \mu^{\mathrm{h}}$ & $1 / \circ \wedge^{g}$ & $\circ / T \& 9 \mathrm{fg}$ & $\circ /$ Tryd-f & $\circ /$ rq e-g & $\circ / Y Y_{\circ} \mathrm{cd}$ & بهار \\
\hline$\circ / 19)^{h}$ & $\circ / \uparrow \Delta q^{b-d}$ & $1 / 1 Q^{g}$ & $1 / 11^{f}$ & $\circ / T V \circ f$ & $\circ / T r V^{f}$ & $\circ / T \Delta \Delta^{c-e}$ & ०/YYqCd & قدس \\
\hline$\circ / \mid \nvdash \varphi^{j}$ & $\circ / \wedge \wedge$ hi & $\circ / 9 \mu \varphi^{n}$ & $\circ / \Lambda 10^{n}$ & $\circ / T Q \circ h$ & $\circ / \Upsilon \wedge \wedge l^{a b}$ & $\circ / Y_{\circ} q^{j}$ & $\circ / T \Delta \Lambda^{a}$ & شيراز \\
\hline $0 / \mid V \psi^{4}$ & $\circ / 4 Y \wedge d-f$ & $1 / 19^{f}$ & $1 / \circ q^{h}$ & $\circ / T \wedge I^{e}$ & $\circ / T \Delta r^{d-f}$ & $\circ / T r V^{f g}$ & o/ MYYcd & كوير \\
\hline$\circ / 10 \Lambda^{j}$ & $\circ / \notin \vee Q^{a b}$ &.$/ 94 \varphi^{n}$ & $\circ / 119^{n}$ & $\circ / r Q r^{j}$ & $\circ /$ YA $y^{a}$ & $\circ / \Upsilon \circ \wedge^{j}$ & $\circ / T \Delta Y^{c a b}$ & الموت \\
\hline$\circ / Y \backslash \circ f g$ & $0 / 4 r q c-e$ & $1 / 11^{i}$ & $1 / 1 \mathrm{Fe}^{\mathrm{e}}$ & $\circ /$ TA de & $0 /$ Y Q qa-d & $\circ / Y G \wedge^{\mathrm{a}-\mathrm{c}}$ & $\circ /$ TMybc & تجن \\
\hline $0 /$ YYqb & $\circ / \mathbb{f} \vee q^{a b}$ & $1 / \circ \wedge^{j}$ & $\circ / 99 Y^{1}$ & $\circ / \Upsilon \varphi D^{f g}$ & $\circ / T \Delta V^{c-f}$ & o/YYrg-j & $\circ / T^{\prime} Y^{b c}$ & خشكى 11 \\
\hline$\circ / Y Y \wedge^{c d}$ & $\circ / 49 r^{a}$ & $1 / \mu^{\mathrm{ab}}$ & $1 / r V^{b}$ & $\circ / \Gamma \circ V^{b}$ & $0 / r \mu q f$ & $\circ / Y V T^{\mathrm{ab}}$ & $\circ / Y \backslash Y^{\mathrm{cd}}$ & شهريار \\
\hline$\circ / Y \mid \mu^{\mathrm{ef}}$ & $\circ / 4 \mid V^{e-g}$ & $1 / \circ 4^{k}$ & 1/ook & $\circ / \Gamma \Delta \wedge^{g h}$ & $\circ / T G \circ$ b-f & $\circ / Y r \Delta^{g-i}$ & o/TYYcd & كارون \\
\hline$\circ / Y I V^{d-f}$ & $\circ / \mu^{\prime} \circ \varsigma^{f-h}$ & $1 / 0 y^{c 1}$ & $1 / \circ \wedge^{g}$ & $\circ / T_{\Delta Q g h}$ & o/ Ty ya-e & $\circ /\left.Y Q\right|^{d-f}$ & ०/YMYbc & گاسيارود \\
\hline o/MYYd-f & $\circ / \mu \Delta Q^{i}$ & $1 / \circ \wedge^{j}$ & $1 / I V^{d}$ & $\circ / Y \varphi_{\circ} \mathrm{f}-\mathrm{h}$ & $\circ / r \Delta r^{d-f}$ & $0 / T \& \mu^{\mathrm{a}-\mathrm{d}}$ & $\circ / Y Y Y c d$ & اميد \\
\hline$\circ / Y y \mid b c$ & $\circ / \uparrow \wedge q^{a b}$ & $|/ \pi|^{\mathrm{c}}$ & $1 / 19^{\mathrm{d}}$ & $0 / T 99 \mathrm{c}$ & o/ Typef & ०/YQYcd & $\circ / Y Y_{\circ} \mathrm{cd}$ & مرودشت \\
\hline
\end{tabular}

در هر ستون و براى هر عامل آزمايشى، تفاوت بين ميانخين هايى كه حداقل داراى يكى حرف مشترك هستند، براساس آزمون LSD در سطح احتمال بنج درصد معنى دار نيست.

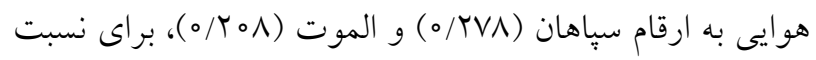

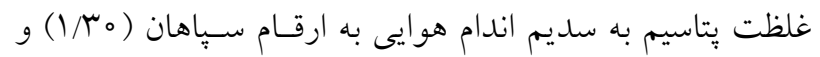

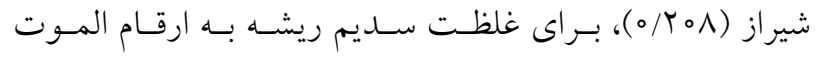

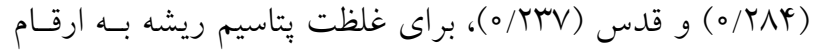

در سطح احتمال ينج درصد معنىدار بود (جدول ()). بيشترين و كمترين غلظت سديم در اندام هوايى بهترتيب بــه ارقسام شسيراز

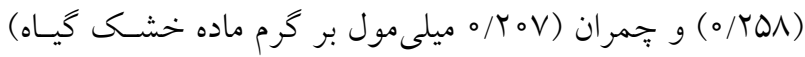
تعلق داشت (جدول Y). اين مقادير براى غلظـت بِتاسـيم انـدام 
جدول r. مقايسه ميانگينهاى غلظت كارتنوئيد (ميلى

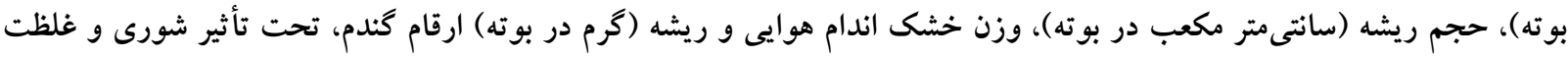
دى اكسيد كربن محيط

\begin{tabular}{|c|c|c|c|c|c|c|}
\hline وزن خشك & وزان خشام هوايى & حجم ريشه & سطح برى & ارتفاع كَاه & كارتنوئيد & عامل آزمايشى \\
\hline & & & & & & $\begin{array}{l}\text { سطح شورى مولار) } \\
\text { (ميلى }\end{array}$ \\
\hline o/rmYa & $\circ / \Lambda \mid q^{a}$ & $r / \varphi \Delta^{a}$ & $99 / \mu^{\mathrm{a}}$ & $\Delta \Lambda / \psi^{\mathrm{a}}$ & $\circ /{ }^{k} V q^{a}$ & صفر \\
\hline \multirow[t]{2}{*}{$\circ / / \vee q^{b}$} & $\circ / \Delta V I^{b}$ & $r / \circ \varphi^{b}$ & $r \circ / r^{b}$ & $r q / \wedge^{b}$ & $\circ / V^{\prime} \wedge^{b}$ & 100 \\
\hline & & & & & & غلظكت دىاكسيد كربن \\
\hline $0 / 199 \mathrm{~b}$ & $0 / 9011^{b}$ & $r / Q V^{b}$ & $01 / 1^{b}$ & $k^{k} / q^{b}$ & $\circ / \mu q 4 b$ & $\mu_{\Lambda}$ \\
\hline \multirow[t]{2}{*}{$o / M I y^{a}$} & $\circ / N \Delta^{a}$ & r/q qa & $\Delta Q / \Delta^{\mathrm{a}}$ & $\Delta r / 0^{a}$ & $\circ / 490 \mathrm{a}$ & Voo \\
\hline & & & & & & رقم \\
\hline$\circ / \Gamma \Lambda \Lambda^{b}$ & $\circ / \Lambda \mid \varphi^{a}$ & $y / \circ q^{a}$ & $90 / 1 \mathrm{bc}$ & $\Delta \Delta / q^{a}$ & $\circ \pi \wedge \mu_{f g}^{f g}$ & سباهان \\
\hline $0 / Y 99^{\circ}$ & $\circ / \sqrt{ } q_{\mathrm{Kbc}}$ & $r / 4 q^{c}$ & $91 / \mathrm{cab}^{\mathrm{ab}}$ & $\Delta \Delta / 1^{\mathrm{a}}$ & o/Qrra & سيستان \\
\hline$\circ / r \mu l^{\mathrm{e}}$ & $\circ / 9 r \Delta^{i}$ & $r / l \varphi^{d}$ & $r \Delta / \mathrm{V}^{\mathrm{i}}$ & $\Delta \circ / \varphi^{\mathrm{cd}}$ & $\circ / \mathrm{r}^{\mathrm{e} \text { ef }}$ & نويد \\
\hline$\circ /|\psi|^{i}$ & $0 / 99 k \mathrm{kh}$ & $r / V l^{\text {hi }}$ & $0 \% \%^{h}$ & $\mathrm{kr} / \mathrm{ok}^{\mathrm{k}}$ & $\circ / 401^{b}$ & شعله \\
\hline$\circ / \circ V V^{1}$ & $\circ / \Delta \wedge q^{j}$ & $1 / Q V^{n}$ & $r y / l^{j}$ & $r Q / q^{\mathrm{ij}}$ & $\circ / \mu Y q h$ & سرختخم \\
\hline$\circ / \Upsilon^{\prime} \wedge \wedge^{\mathrm{fg}}$ & $\circ / V \circ \Delta^{f}$ & $r / \Delta V^{j}$ & $90 / 1 \mathrm{bc}$ & $\mathrm{FV} / \mathrm{V}^{\mathrm{gh}}$ & $\circ / \wedge \kappa_{f g}$ & بيشتاز \\
\hline a & $\circ / N 0^{\circ} \mathrm{cd}$ & $r / N \Lambda^{g h}$ & $G 4 / N^{\mathrm{a}}$ & $01 / \mathrm{rbc}^{\mathrm{bc}}$ & $\circ / 4 T_{0} \mathrm{bc}$ & جمران \\
\hline$\circ / r \Delta \Delta^{d}$ & $\circ / 90 V^{g h}$ & $T / N V^{h}$ & $\Delta r / /^{f-h}$ & $r \Delta / r^{j}$ & $0 / M Y_{0} \mathrm{c-e}$ & كرج \\
\hline $0 / r$ re & $0 / 9 Y \Lambda^{i}$ & $\mathrm{r} / \mathrm{orm}$ & $\Delta Y /$ ogh & $Y_{N} / \Delta^{\mathrm{fg}}$ & $0 / 4 r q^{b-d}$ & كهار \\
\hline.$/ 199^{h}$ & $0 / 94 \Delta^{h i}$ & $r / \mu q^{k}$ & $\Delta \psi / N^{d-g}$ & $r q / q^{d-f}$ & o/drva & ق ق \\
\hline.$/ \circ 99^{k}$ & $\circ / \Delta \wedge Y^{j}$ & $r / \circ \Delta^{m}$ & $r \circ / V^{j}$ & $\varphi \varphi / \Lambda^{\mathrm{hi}}$ & $0 / 449 \mathrm{gh}$ & شيراز \\
\hline $0 /\left.|\psi|\right|^{i}$ & $\circ / N r T_{d e}$ & $r / / Y^{1}$ & $\Delta F / r^{d-g}$ & $r q / \mu d-f$ & o/frybbc & كوير \\
\hline$\circ / 1 / \varphi^{j}$ & $\circ / 9 \circ \circ j$ & $r / 4 Y^{k}$ & $\mu N / \Delta^{j}$ & $\uparrow \& / q^{\mathrm{hi}}$ & $\circ / T V Q^{I}$ & الموت \\
\hline $0 / / \mu \mu_{i}$ & $\circ / V \wedge \circ b$ & $r / \Lambda g^{e f}$ & $\Delta r / \wedge^{e-g}$ & $Y Y / 0^{k l}$ & $0 / \mathbb{c}_{0} / l^{\mathrm{d}-\mathrm{e}}$ & تجن \\
\hline o/rrye & $\circ / V V Y^{b c}$ & r/que & $\Delta G / Y^{\mathrm{d}-\mathrm{f}}$ & $0 . / 9^{1}$ & $0 / 4 k q^{b}$ & خشكى 1" \\
\hline$\circ / Y \wedge \vee^{b}$ & o/VGYbc & $r / q \mu^{b}$ & $9 \circ / r^{b c}$ & $\Delta r / I^{b}$ & o bc be be & شهريار \\
\hline$o / r \mid r^{f}$ & $0 / 9 \vee 9 g$ & $r / 99^{\circ}$ & $\Delta r / q^{\mathrm{fth}}$ & $\times 9 / l^{\text {ef }}$ & $0 / 4 r q^{b-d}$ & كارون \\
\hline$\circ / r Y \wedge^{e}$ & $0 / 99 \wedge \mathrm{g}$ & $r / M^{e f}$ & $\Delta V / /^{c-e}$ & $r q / \Lambda^{\mathrm{de}}$ & $\circ / \Delta \Delta \Delta^{a}$ & كاسبهارود \\
\hline$\circ / 19 / \mathrm{g}$ & $\circ / V \backslash \Lambda^{e f}$ & $r / \Lambda \Delta^{\mathrm{fg}}$ & $\Delta / / \wedge^{\mathrm{gh}}$ & $Y \wedge / q^{e-g}$ & $T /$ q Trbbc & اميد \\
\hline$\circ / T V \wedge^{\mathrm{bc}}$ & $\circ / V Y I^{e f}$ & $r / 1 q^{d}$ & $\Delta V / \varphi^{c d}$ & $01 / q^{b}$ & $\circ / 4 \Delta \& b$ & مرودشت \\
\hline
\end{tabular}


جدول ثا. برهمكنش اثر شورى و دىاكسيد كربن بر غلظت بتاسيم اندام هوايى و ريشه (ميلىمول بر گرم وزن خشك)، نسبت بِتاسيم به

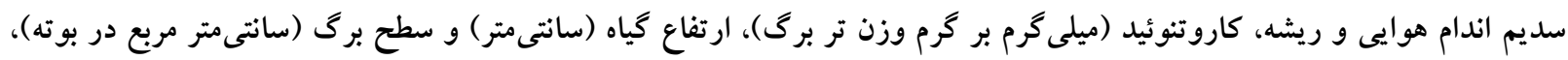

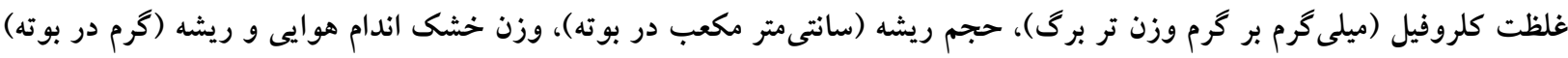

غلظت دىاكسيد كربن (ميكرومول بر مول)

\begin{tabular}{|c|c|c|c|c|}
\hline \multicolumn{2}{|c|}{ Vo。 } & \multicolumn{2}{|c|}{$r_{1}$} & \multirow{2}{*}{ صفات اندازهيرى شده } \\
\hline إما ميلى مولار & صفر ميلى مولار & إما ميلى مولار & صفر ميلى مولار & \\
\hline$\circ / Y \mid \varphi^{b}$ & $\circ / r a r^{a}$ & $\circ / 199 \mathrm{c}$ & $\circ / T V G a$ & يتاسيم اندام هوايى \\
\hline$\circ / \Lambda \Lambda \gamma^{c}$ & $1 / 90^{a}$ & $\circ / V \backslash \Lambda^{d}$ & $1 / \wedge^{\mathrm{b}}$ & نسبت يتاسيم به سديم اندام هوايى \\
\hline$\circ / \Gamma 19 c^{c}$ & $\circ / \Gamma \Delta \wedge^{a}$ & $\circ / 190^{d}$ & $\circ / \mu \Lambda^{b}$ & يتاسيم ريشه \\
\hline o/ATGC & $1 / 99^{\circ}$ & $\circ / 9 Y I^{d}$ & $1 / 0 \circ b$ & نسبت يتاسيم به سديم ريشه \\
\hline$\circ / c^{\circ} \circ r^{\mathrm{b}}$ & $\circ / D / q^{a}$ & $\circ \mu \Delta \mu^{c}$ & $0 / 4 r q b$ & كاروتنوئيد \\
\hline$r Q / q^{c}$ & $90 / 1^{a}$ & $r \mu / 9 \mathrm{~d}$ & $\Delta g / T^{b}$ & ارتفاع كياه \\
\hline$K T / V^{b}$ & $9 N / T^{a}$ & $r V / q c$ & $94 / r^{a}$ & سطح برى \\
\hline$\circ / M_{1}$ & o/DYva & $0 / M Y l^{d}$ & $\circ / \mathrm{qVab}^{-}$ & a كلروفيل a \\
\hline$\circ / \wedge \wedge q^{c}$ & $\circ /\left.Y \varphi\right|^{a}$ & $\circ / Q Q r^{d}$ & $0 / r \wedge^{b}$ & كلروفيل b \\
\hline$r / T r^{\mathrm{c}}$ & $r / v^{a}$ & $r / o^{d}$ & $r / 10^{b}$ & حجم ريشه \\
\hline$\circ / \wedge \& q^{\prime}$ & $0 / 9 Y T^{C}$ & $\circ / V \wedge r^{b}$ & $\circ / 019^{d}$ & وزن خشك اندام هوايى \\
\hline$\circ / 1 \wedge q^{b}$ & $\circ / Y_{\circ} a^{a}$ & $\circ / 19 \Lambda^{c}$ & $0 /$ TYa & وزن خشك ريشه \\
\hline
\end{tabular}

براى هر صفت، تفاوت بين ميانكينهايى كه حداقل داراى يك حرف مشترى هستند، براساس آزمون LSD در سطح احتمال بِنج درصد معنى دار نيست.

نتايج نشان مىدهد كه تـأثير مثبـت افـزايش غلظـت دى اكسـيد كربن در شرايط شور بيشتر بوده است. بهنظر مىرسد در شرايط

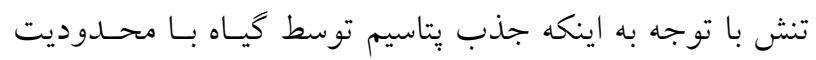

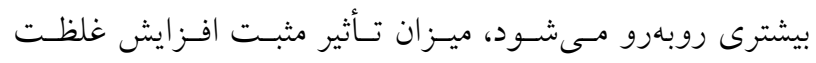

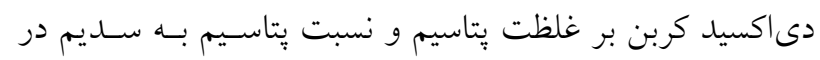

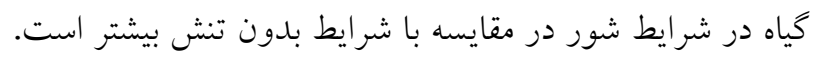

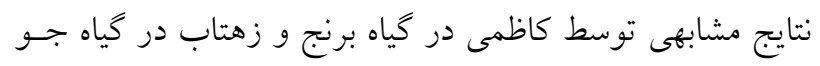

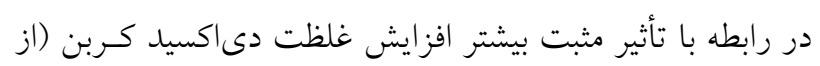

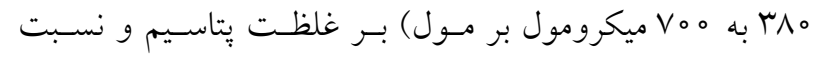
غلظت يتاسيم به سديم در اندام هوايى و ريشه در شرايط شـور

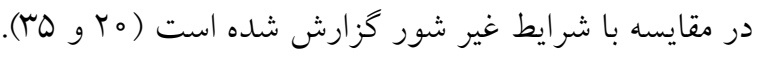

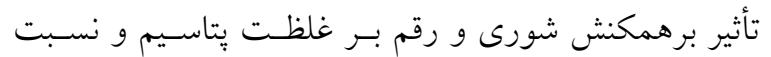

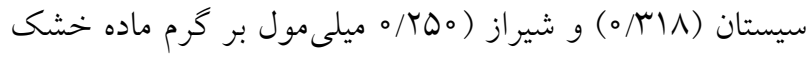

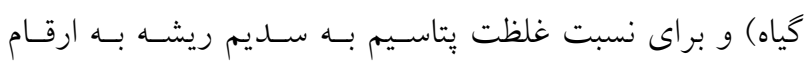

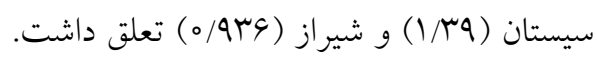

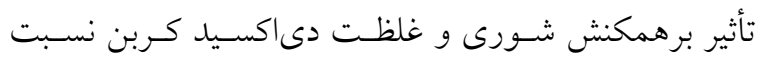

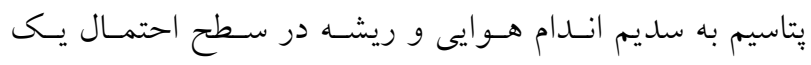

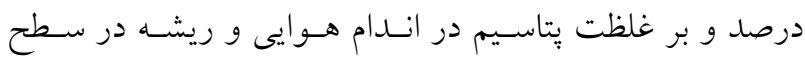

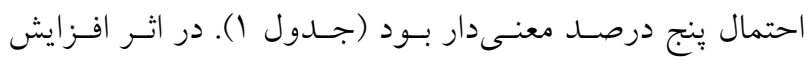

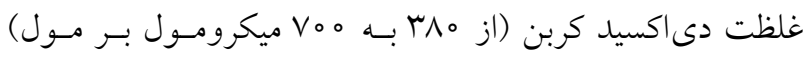

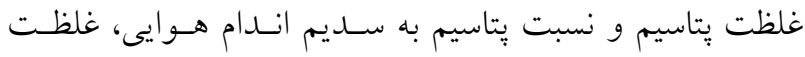

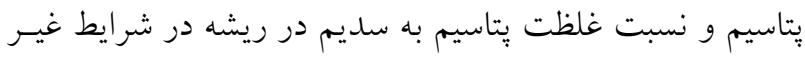

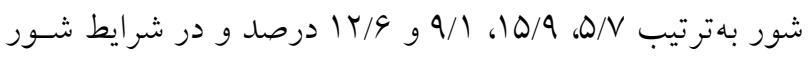

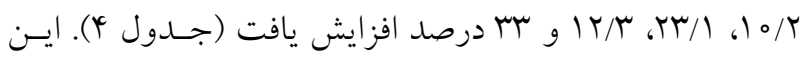


جدول ه. برهمكنش اثر شورى و رقم بر غلظت سديم و يّاسيم (ميلىمول بر گرم وزن خشك) اندام هوايى و ريشه و نسبت يتاسيم به سديم اندام هوايى

\begin{tabular}{|c|c|c|c|c|c|c|c|c|c|c|}
\hline \multicolumn{2}{|c|}{ سديم اندام هوايى بتاسيم به } & \multicolumn{2}{|c|}{ يتاسيم ريشه } & \multicolumn{2}{|c|}{ سديم ريشه } & \multicolumn{2}{|c|}{ يتاسيم اندام هو ايیى } & \multicolumn{2}{|c|}{ سديم اندام هوايى } & \multirow[t]{2}{*}{ ارقام گندم } \\
\hline 100 & صفر & $10 \circ$ & صفر & 100 & صفر & 100 & صفر & 100 & صفر & \\
\hline$\circ / \Lambda \wedge \circ 0$ & $1 / 91^{a}$ & o/Trufg & $\circ / \Upsilon \wedge \xi^{a b}$ & $0 / Y q 1$ a-f & $\circ /$ Yooh & o/TYYg-m & ./MTra & $\circ / Y \Delta Y^{a-h}$ & $\circ / I V Y^{k g h}$ & سياهان \\
\hline$\circ / \Lambda \circ \Delta^{p}$ & $1 / 9 \circ a$ & $0 / \pi \mu q f$ & $\circ / 4 q V^{a}$ & $\circ / \mu \mu^{a-e}$ & $0 / 199^{\mathrm{h}}$ & $\circ /\left.T \backslash\right|^{\mathrm{h}-\mathrm{m}}$ & $\circ / \pi q^{a}$ & o/ T\&Ya-g & $\circ / I V q^{e-h}$ & سيستان \\
\hline $0 / 994 t$ & $1 / 9 V^{d}$ & $\circ / Y \circ \mu^{f-i}$ & $\circ /$ rVyab & $\circ \mu \circ \mu^{a-e}$ & $\circ / Y \circ \varphi_{\mathrm{gh}}$ & $\circ / / V^{l m}$ & $\circ / \mu \mid \Lambda^{\mathrm{a}-\mathrm{c}}$ & $0 /$ r\&qa-d & $\circ / / \wedge q^{c-h}$ & نويد \\
\hline $1 / 1 \mu^{c j}$ & $1 / \mu r^{h}$ & $\circ / T \circ q^{f-i}$ & - $/ \omega \Delta r^{b-d}$ & $0 / / 9 V^{a-f}$ & $\circ / T_{0} /^{h}$ & $\circ / T \Delta \wedge^{\mathrm{e}-\mathrm{h}}$ & $0 / T V \mu^{\mathrm{b}-\mathrm{g}}$ & $0 /$ TYka-h & $\circ / T \circ \varphi^{a-h}$ & شعله \\
\hline$\circ / 099^{u}$ & $1 / 19^{j}$ & $\circ / 1 \circ q^{j}$ & $\circ / \mu Y_{0} \mathrm{de}$ & $\circ / \mu \mid \varphi^{\mathrm{a}-\mathrm{c}}$ & $\circ / \Gamma \Lambda^{\mathrm{b}-\mathrm{h}}$ & $0 / \| V^{m}$ & $\circ / Y Q Q^{\mathrm{e}-\mathrm{h}}$ & $\circ / \Upsilon \wedge \Lambda^{\mathrm{ab}}$ & $\circ / Y \backslash 9^{\mathrm{a}-\mathrm{h}}$ & \\
\hline$\circ / N^{m}$ qr & $1 / 44 \mathrm{~g}$ & $0 / 19 /^{g-i}$ & & $\circ / Y V y^{a-h}$ & $\circ / Y \circ Y^{h}$ & $\circ /\left.\backslash \wedge\right|^{\mathrm{lm}}$ & $0 / Y \& q^{b-g}$ & o/YYYa-h & $\circ / \Lambda \wedge Y^{d-h}$ & \\
\hline$\circ / \Lambda / \wedge^{p}$ & $1 / A c^{c b}$ & $0 / T \mid c^{\mathrm{f}-\mathrm{i}}$ & $\circ / \mu G \wedge^{a b}$ & $\circ / Y \vee q^{a-h}$ & $\circ / 19 \wedge^{\mathrm{h}}$ & $\circ /\left.Y \circ\right|^{i-m}$ & $\circ / \mu \mid \Delta^{\mathrm{a}-\mathrm{d}}$ & $\odot / Y Y \Delta^{\mathrm{a}-\mathrm{h}}$ & $0 / 199^{h}$ & جمران \\
\hline $0 / 999^{\mathrm{st}}$ & $1 / \Psi^{*} \wedge^{g}$ & $0 / 19 V^{g-i}$ & $\circ / \Gamma I V d e$ & $0 / r q Y^{a-f}$ & o/rYG d-h & $\circ / \Lambda \Lambda \mu^{\mu l m}$ & $0 / T V I^{b-g}$ & - T\& & $\circ / \backslash \wedge Y^{\mathrm{d}-\mathrm{h}}$ & كرج \\
\hline o/varqr & $1 / \Delta V^{e}$ & $0 / Y \mid Y^{f-i}$ & ०MYode & o/ropa-h & $\circ / Y \mu^{\mathrm{b}-\mathrm{h}}$ & $\circ / 19 \mu^{\mathrm{k}-\mathrm{m}}$ & $\circ / T \wedge c^{a-f}$ & $\circ / Y \Delta q^{a-g}$ & $\circ / \Lambda \wedge Y^{d-h}$ & بهار \\
\hline$\circ / 9 \wedge \mu^{m}$ & $1 / T^{h i}$ & $0 / T / r^{f-i}$ & $0 / T \Lambda^{c-e}$ & o/TyYa-h & $0 / T \mu Y^{c-h}$ & $0 / T \& \varphi^{\mathrm{b}-\mathrm{g}}$ & o/ Trye-k & $0 /\left.T V\right|^{a-c}$ & $\cdot / \wedge \Lambda^{c-h}$ & قدس \\
\hline$\circ / \Delta \wedge \mu^{u}$ & $1 / 10^{k}$ &.$/ 191^{i}$ & $\circ / \Gamma \circ q e$ & $\circ / \mu / q^{a b}$ & o/Typa-h & $\circ / I V \circ m$ & $\circ / T{ }^{c} \wedge \wedge^{e-j}$ & $\circ / 491 \mathrm{a}$ & o/TYYa-h & 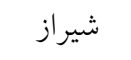 \\
\hline$\circ / N I V^{r s}$ & $1 / \Delta r^{f}$ & $\circ / \Gamma \circ \circ g-i$ & $\circ$ MSYa-c & $\circ / Y q \mid a-f$ & $\circ / Y \backslash Q^{f-h}$ & $\circ / \bigwedge \wedge k \operatorname{lm}$ & $\circ / Y q \circ a-e$ & - Y YQYa-h & $\circ / \backslash \wedge q^{c-h}$ & كوير \\
\hline.$/ 09 V^{u}$ & $1 / 1 \varphi^{{ }^{j} j}$ & $\circ / 19$ rhi & $\circ / \mu / K^{\mathrm{ee}}$ & $\circ / r Y V^{a}$ & $0 /$ TyYa-h & $\circ / I V \Delta^{m}$ & o/TYY Ye-k & $0 / r q 4 a$ & $\circ / r \mid \varphi^{\mathrm{b}-\mathrm{h}}$ & الموت \\
\hline $1 / \circ r^{1}$ & $\mid / \mu^{j \mathrm{jk}}$ & $\circ / T \circ V^{f-i}$ & $0 /\left.\mu\right|^{a-c}$ & $\circ / \mu r^{a-e}$ & o/rmab-h & $\circ / T r^{\mathrm{b}-\mathrm{g}}$ & $0 /$ $\& \psi^{\mathrm{c}-\mathrm{h}}$ & $\circ / T \& V^{a-e}$ & $\circ / Y \circ \circ b-h$ & تجن \\
\hline$\circ / 99 \circ$ st & $1 / \mu T^{h}$ & $\circ / T \circ V^{f-i}$ & o/Mrrde & $\circ /\left.Y q\right|^{a-f}$ & o/YYrd-h & 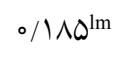 & $0 /\left.r \&\right|^{\mathrm{d}-\mathrm{h}}$ & $\circ / Y G \wedge^{\mathrm{a}-\mathrm{d}}$ &.$/ 199^{c-h}$ & خشكى || \\
\hline & $1 / 91^{a}$ & $0 / Y Y q^{f-h}$ & $\circ / \Upsilon \wedge \Delta^{a b}$ & $\circ / \zeta \wedge \circ a-h$ & $\circ / 19 \wedge^{\mathrm{h}}$ & $\circ /\left.T \backslash\right|^{\mathrm{h}-\mathrm{m}}$ & & $\circ / Y \Delta r^{\mathrm{a}-\mathrm{h}}$ & $\circ / I V Q^{f-h}$ & شهريار \\
\hline$\circ / V G \mid q$ & $1 / T G^{\mathrm{i}}$ & $0 / 1999-\mathrm{i}$ & $\circ / \Gamma I V d e$ & $\circ / \mu_{0} \varphi^{a-e}$ & $\circ / Y \mid \varepsilon^{\mathrm{f}-\mathrm{h}}$ & -/IVqlm & $0 / T V I^{b-g}$ & $\circ / T r \Delta^{a-h}$ & $0 / Y \mid Y^{a-h}$ & كارون \\
\hline $0 / 9 r \& n$ & $1 / 19^{h i}$ & $\circ / Y \circ \mu^{f-i}$ & $\circ /$ Me & $\circ / \sim q^{a-d}$ & $\circ / Y 19 \mathrm{e}-\mathrm{h}$ & o/TOYe-i & $\circ /\left.T \Delta\right|^{e-i}$ & $\circ / Y V Y^{a-c}$ & $\circ / 19 r^{c-h}$ & كاسيارود \\
\hline ०/ $৭ 99^{\text {no }}$ & $1 / \Delta \Delta^{\mathrm{ef}}$ & $\circ / Y \circ Y^{f-i}$ & $\circ / \mu \backslash \wedge$ de & $\circ / \curlyvee \wedge q^{a-g}$ & $\circ / Y \mid q^{f-h}$ & & $0 /$ Yqa-e & $0 / Y \varphi_{\circ} \mathrm{a}-\mathrm{g}$ & $\circ / \backslash \wedge \wedge^{c-h}$ & اميد \\
\hline - NDQGa & $1 /\left.V\right|^{c}$ & $\circ / Y_{0} \mathrm{f}_{-\mathrm{i}}$ & $\circ / V^{a}$ & $\circ / \Upsilon \wedge r^{a-h}$ & $\circ / Y \circ r^{g h}$ & $\circ / / 9 r^{\mathrm{j}-\mathrm{m}}$ & $\circ / T_{1} q^{a b}$ & - TUQGa-h & $0 / \backslash \wedge \psi^{c-h}$ & مرودشت \\
\hline
\end{tabular}

براى هر صفت، تفاوت بين ميانكينهايى كه حداقل داراى يك حـرف مشـترك هسـتند، براسـاس آزمـون LSD در سـطح احتمـال بـنج درصـد

تجن از نظر آمارى معنىدار نبـود. بيشـترين و كمتـرين كـاهش

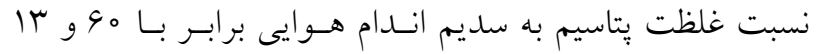
درصد بهترتيب به ارقام نويد و شعله، بيشترين و كمترين كاهش غلظت يتاسيم ريشه برابر ها و هـ درصد به ارقام نويـــ و بهـار (جدول ه) و بيشترين و كمترين كاهش نسبت غلظت يتاسيم به سديم ريشه برابر سو و باس درصد به ارقـام نويـــ و بهـار تعلـق داشت (جدول 9). در اثر شورى غلظت ســيم انسام هـوايى و ريشه در كليه ارقام افزايش يافت. بيشـترين و كمتـرين افـزايش غلظت سديم اندام هوايى برابر اسو م درصد بهترتيب به ارقـام سيستان و شعله ولى بيشترين و كمترين افزايش غلظـت سـديم ريشه برابر Or و \& د درصد به ارقام سيستان و قدس تعلق داشـت
غلظت يتاسيم به سديم اندام هـو ايى، غلظـت يتاسـيم، ســـيم و

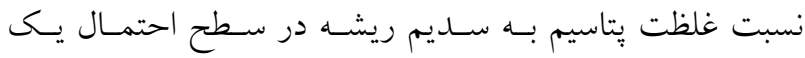
درصد و بر غلظت سديم انـام هـوايى در سـطح احتمـال يـنج درصد معنى دار شد (جدول (). در اتــر شـورى غلظـت بتاسـيم اندام هوايى در كليه ارقام بهاستثناى رقم قدس و تجن و نسـبت غلظت يتاسيم به سديم اندام هوايى، غلظت يتاسيم (جدول ه) و نسبت غلظت بيتاسيم به سديم ريشه (جــدول 9) در كليـه ارقـام بهاستثناى ارقام قدس و تجن كاهش يافت. بيشـترين و كمتـرين

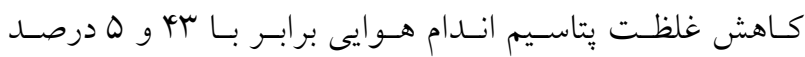
بهترتيب به ارقام نويد و شعله تعلـق داشـت (جــدول ه). تـأثير تنش شورى بر غلظت يُّاسـيم در انــام هــوايى ارقـام قـدس و 
جدول 9. برهمكنش اثر شورى و رقم بر نسبت بتاسيم به سديم ريشه، غلظت كلروفيل و كاروتنوئيد (ميلى

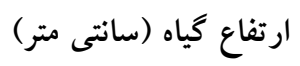

\begin{tabular}{|c|c|c|c|c|c|c|c|c|c|c|}
\hline \multicolumn{2}{|c|}{ ارتفاع گياه } & \multicolumn{2}{|c|}{ كاروتنوئيد } & \multicolumn{2}{|c|}{ كلروفيل b } & \multicolumn{2}{|c|}{ a كلروفيل a } & \multicolumn{2}{|c|}{ نسهبت سبتاسيم } & \multirow[t]{2}{*}{ ارقام گندم } \\
\hline $10 \circ$ & صفر & $10 \circ$ & صفر & $10 \circ$ & صفر & $10 \circ$ & صفر & $10 \circ$ & صفر & \\
\hline$\varphi \Delta / \mu^{\mathrm{ij}}$ & $99 / 0^{\mathrm{a}}$ & $\circ / \mu_{\circ} \mathrm{m}-\mathrm{o}$ & $0 / 4 \uparrow q e-1$ & $\circ / \mu_{1} \circ \circ^{a}$ & $\circ / Y \wedge \Lambda^{\mathrm{ab}}$ & $\circ / \mathbb{r} r \Delta^{c-k}$ & $\circ /\left.01\right|^{a-d}$ & $\circ / \Lambda / \circ 0$ & $1 / 9 \mu^{b}$ & سياهان \\
\hline$\mu Y^{\mathrm{F}} / \mathrm{V}^{\mathrm{ij}}$ & $9 \mathrm{Q} / \varphi^{\mathrm{ab}}$ & $0 / 49 V^{d-i}$ & $\circ / 09 \mathrm{Vbc}$ & $\circ / \mu \circ r^{a}$ & $\circ / \Upsilon 9 \Delta^{\mathrm{ab}}$ & $\circ /{ }^{\mathrm{m}} \mid \varphi_{\mathrm{k}-\mathrm{m}}$ & $0 / \uparrow \wedge y^{c-e}$ & o/vato & $1 / 99^{a}$ & سيستان \\
\hline$r q / T^{k-m}$ & $91 / \mathrm{V}^{\mathrm{b}-\mathrm{e}}$ & $\circ / \mu Y V^{j-n}$ & o/ $y<q$ e-k & $0 / / T r_{\mathrm{q}-\mathrm{t}}$ & $0 / T V Y^{a-d}$ & $\circ / \mu_{\circ} \circ \mathrm{lm}$ & $\circ / \mathcal{Y} \wedge \circ a-e$ & $0 / 9 V Y^{4 r}$ & $1 / \Lambda r^{c o}$ & نويد \\
\hline$\left|x_{1}\right| \mathrm{r}^{\mathrm{j}-1}$ & $\mu \psi / / \Lambda^{i j}$ & $\circ / 4 \circ \varphi^{\mathrm{e}-\mathrm{n}}$ & $0 / 490^{c-f}$ & $0 / / Y<q-t$ & $0 / Y Y I^{\mathrm{d}-\mathrm{k}}$ & $\circ / \mu\rangle^{g-m}$ & $\circ / 0 \cdot q^{a-d}$ & $\circ / N \circ \wedge^{q r}$ & $1 / V \varphi^{d}$ & شعله \\
\hline$r \Delta / \varphi^{m}$ & $\Delta \Delta / q^{f g}$ & o/MYYm-o & $\circ M_{V} \varphi^{i-n}$ & $\circ / \circ V q t$ & $\circ / \mid V Y^{\mathrm{c}-q}$ & $\circ /\left.\mathbb{f}_{0}\right|^{\mathrm{d}-1}$ & $0 /\left.4 \&\right|^{a-h}$ & $0 / 91 y^{\text {st }}$ & $1 / \mu \mu^{j k}$ & \\
\hline $\mathrm{rV} / \mathrm{Q}^{\mathrm{lm}}$ & $\Delta \Lambda / \circ$ ef & o/Ky<k-o & o/fype-m & $\circ / T \backslash \wedge \wedge^{\mathrm{e}-1}$ & $\circ / Y \mid Y^{f-m}$ & $\circ /\left.\mu\right|^{j-m}$ & o/OYYa-c & ०/NYrpq & $1 / 0 q^{f}$ & بيnتاز \\
\hline$\Upsilon_{\Lambda / \Upsilon^{l m}}$ & $G y^{p a-c}$ & $\circ / N \vee q^{h-n}$ & $\circ / \mathcal{A} \wedge Y^{d-i}$ & $\circ / \mid V{ }^{j-q}$ & $\circ / T \vee Q^{\mathrm{a}-\mathrm{c}}$ & $\circ / r V r^{e-m}$ & -/DG Vab & -/VAYop & l/^ৎc & جّمران \\
\hline$\mu \psi / \Delta^{i j}$ & $\varphi \Delta / q^{i j}$ & $\circ / \Lambda \wedge V^{f-n}$ & $\circ / \mathcal{H} \Delta \mu^{\mathrm{e}-\mathrm{j}}$ & $\circ / 10 \circ$ o-r & $\circ / Y Y V^{c-i}$ & o/rYs & $0 / 4 q \wedge^{\mathrm{a}-\mathrm{d}}$ & $\circ / 9 \vee १ q r$ & $1 / \varphi_{0} \mathrm{hi}$ & كرج \\
\hline $\mathrm{rg} / \mathrm{cm}$ & $4 \circ / \Delta^{c-f}$ & $\circ / \Lambda r^{h-n}$ & $\circ / \notin V \psi^{\mathcal{d}-\mathrm{i}}$ & $0 /\left.|\psi|\right|^{p-s}$ & $\circ / Y r \Delta^{c-h}$ & $\circ / 4 r \Lambda^{c-k}$ & o/Orya-c & $\circ / \wedge q \mathrm{rm}^{\mathrm{m}}$ & $1 / \Gamma V^{i j}$ & \\
\hline$r q / v^{k-m}$ & $\Delta Q / \Delta^{d-f}$ & $. / 01 / 1^{c-e}$ & - $/ 0 q$ Y $^{\mathrm{cd}}$ & $\circ / / Q V^{n-q}$ & $\circ / T Y \Delta^{c-j}$ & 足 & $\circ / 0 \wedge)^{a}$ & - /AVA ${ }^{\mathrm{mn}}$ & $1 / 4 Y^{g-i}$ & قدس \\
\hline$\Gamma \Delta / \wedge^{m}$ & $\Delta V / V^{e f}$ & & $0 /\left.\mathbb{f}^{\circ}\right|^{\mathrm{f}-\mathrm{n}}$ & $\circ / \circ q \mu^{\text {st }}$ & $\circ / 19 \wedge^{g-0}$ & $\circ /$ TVGm & $\circ / \mathcal{\Psi} \wedge V^{a-e}$ & $\circ / 90 y^{\text {st }}$ & $1 / T q^{1}$ & شيراز \\
\hline 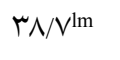 & $90 / 0 \mathrm{clf}$ & $\circ / q V^{f-n}$ & $\circ / Y V Y^{a}$ & $0 / 19 \wedge^{1-q}$ & $\circ / \backslash \wedge)^{i-p}$ & $\circ / Y \Delta^{j-m}$ & $\circ / \Delta \mu_{\circ} a-c$ &.$/ 9949 \mathrm{r}$ & $1 / 9 \wedge^{\mathrm{e}}$ & كوير \\
\hline $\mathrm{r} \omega / \mu_{\mathrm{m}}$ & $\Delta V / q^{e f}$ & $\circ / \mu^{\prime} \wedge^{\circ}$ & $\circ / \mu_{1} Y^{\text {no }}$ & $\circ / 1 \circ \mu^{r-t}$ & $\circ / r \mid c e-m$ & $\circ / 4 \Delta \bullet^{b-i}$ & $\circ / 0 \circ \circ^{a-d}$ &.$/ 0 Q Y^{t}$ & $1 / \mu_{0} \mathrm{kl}$ & الموت \\
\hline$r V / r l m$ & $\varphi \varphi / \wedge^{\mathrm{hi}}$ & $\circ / \mu \psi^{j}{ }^{j-n}$ & $\circ / \mathcal{Y} \Delta \gamma^{c-j}$ & $\circ / I V Y^{\mathrm{k}-\mathrm{q}}$ & $0 /$ Y \&qb-g & $\circ / T \Delta r^{f-m}$ & - Drpa-d &.$/ 9 \wedge 9 q \mathrm{r}$ & $1 / \Delta f^{f f}$ & تجن \\
\hline$\kappa / D^{i-k}$ & $\Delta \wedge / \mu^{\mathrm{ef}}$ & $\circ /\left.4 \backslash\right|^{e-n}$ & $\circ / \uparrow \wedge \varphi^{\mathrm{d}-\mathrm{h}}$ & $\circ / Y Y V^{c-i}$ & $\circ / Y \varphi \Delta^{\mathrm{a}-\mathrm{e}}$ & $\circ /$ rVYe-m & $\circ / \Delta \wedge I^{a}$ & $\circ / \mathrm{Vl} \circ \mathrm{qr}$ & $1 / 4 \Delta g h$ & خشكى 11 \\
\hline$\Delta T / V^{g}$ & $\Delta / \Delta^{\mathrm{gh}}$ & $\circ / \Lambda^{f-n}$ & $0 / 4 \gamma^{d-i}$ & o/ $\mid q \mu^{m-q}$ & $0 / K a y^{c a b}$ & $0 / 4 \& \Delta^{\mathrm{a}-\mathrm{g}}$ & - /Orra-d & -/AYǴno & $1 / 9 q^{a b}$ & شهريار \\
\hline ऍ & $90 / 0 \mathrm{c}-\mathrm{f}$ & $\circ / \uparrow \wedge \varphi^{\mathrm{g}-\mathrm{n}}$ & 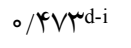 & $\circ / \Lambda \mu^{o-r}$ & $\circ / T V r^{a-c}$ & & $\circ / 4 q \wedge^{\mathrm{a}-\mathrm{d}}$ &.$/ 909 \mathrm{rs}$ & $1 / \mathcal{F}^{\mathrm{g}}$ & كارون \\
\hline $\mathrm{rq} / \mathrm{cm}$ & $q \mu / /^{a-d}$ & $\circ / 4 \backslash q$ e-n &.$/ 991 \mathrm{~b}$ & $\circ / \mid V \psi^{\mathrm{j}-q}$ & $0 / Y \& \mid$ a-f & $\circ /$ wypf-m & $\circ / 4 G \wedge^{\mathrm{a}-\mathrm{f}}$ & $0 /\left.99\right|^{\mathrm{rs}}$ & $1 /$ ergh & كاسيارود \\
\hline $\mathrm{rg} / \mathrm{cm}$ & $91 / \mathrm{T}^{\mathrm{eb}-\mathrm{e}}$ & $\circ / V y^{i-n}$ & $0 / 4 q \psi^{c-g}$ & $\circ / \Lambda \wedge y^{c h-p}$ & $\circ / T \varphi_{\circ} \mathrm{a}-\mathrm{f}$ & $\circ / T V Y^{c m}$ & $0 / f y<b-j$ & $\circ /\left.\mathrm{N} 0\right|^{q r}$ & $1 / \Psi^{q g}$ & اميد \\
\hline$r q / v^{k-m}$ & $q 4 / /^{\mathrm{a}-\mathrm{d}}$ & $\circ / \mu \Delta^{f-n}$ & $\circ / D / r^{\mathrm{c}-\mathrm{e}}$ & $\circ / Y \circ V^{g-n}$ & $\circ / T V \Delta^{\mathrm{a}-\mathrm{c}}$ & o/ सr V vc-k & $\circ /\left.\Delta \forall\right|^{a-c}$ & $\circ / \mathrm{VV} V^{\mathrm{op}}$ & $1 / \Lambda r^{c c}$ & مرودشت \\
\hline
\end{tabular}

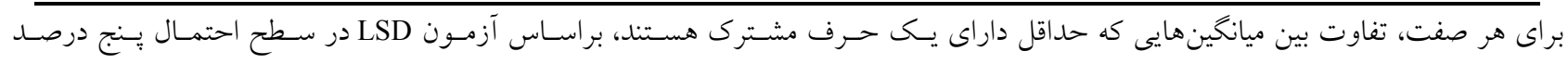

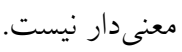

غنى سازى غلظت دى اكسيد كربن، غلظت يتاسيم اندام هوايى را

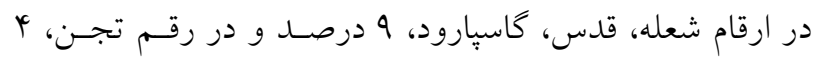

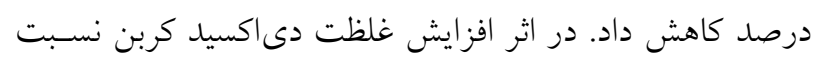

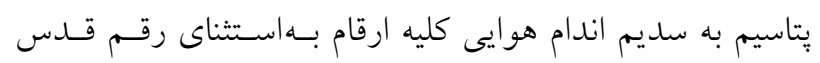

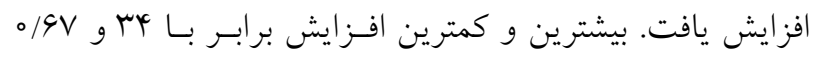

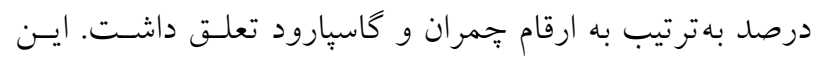

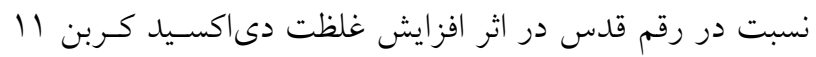

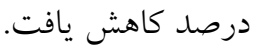

\section{غلظت كلروفيل و كاروتنوئيد} تأثير شورى بر غلظت كلروفيل a و b و غلظـت كاروتنوئيسـ در
(جدول ه). در آزمايش فرهودى نيز تأثير بـرهمكنش شـورى و

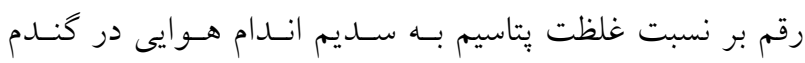

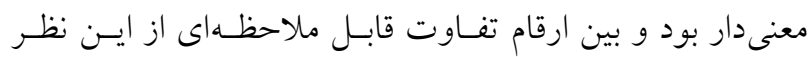
وجود داشت (r) - (I).)

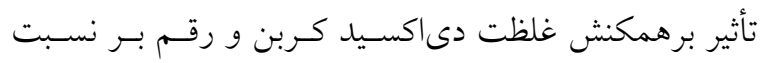

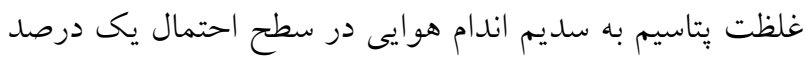

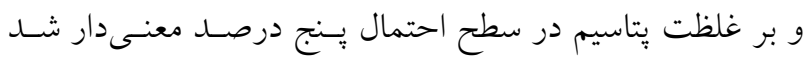
(جدول (). در اثر افزايش غلظت دى باكسيد كربن غلظت بِّاسيم اندام هوايى كليه ارقام بهاستثناى رقم شعله، قـــس و كاسـبِارود افزايش يافت (جدول ^). بيشترين و كمترين افزايش برابر 19 و

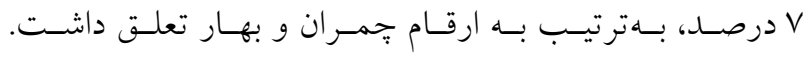


جدول V. برهمكنش اثر شورى و رقم بر سطح برگ (سانتىتر مربع در بوته)، حجم ريشه (سانتىتر مكعب در بوته) و وزن خشك اندام هوايى و ريشه (كرم در بوته)

\begin{tabular}{|c|c|c|c|c|c|c|c|c|}
\hline \multicolumn{2}{|c|}{ وزن خشك ريشه } & \multicolumn{2}{|c|}{ وزن خشك اندام هو ايى } & \multicolumn{2}{|c|}{ حجم ريشه } & \multicolumn{2}{|c|}{ سطح برى } & \multirow{2}{*}{ ارقام كندم } \\
\hline 100 & صفر & $10 \circ$ & صفر & 100 & صفر & $10 \circ$ & صفر & \\
\hline$\circ / T Q \circ f-j$ & o/TYGbc & $\circ / 9 \wedge \wedge^{g-i}$ & $\circ / 9 Y Q^{a}$ & $T / 99 \mathrm{gh}$ & $\Delta / 1 \mu^{a}$ & $\Delta r / /^{d-j}$ & $9 \mathrm{~V} / \mathrm{r}^{\mathrm{a}-\mathrm{d}}$ & سياهان \\
\hline$\circ / T r V^{h-j}$ & $\circ / \mu_{0} / \mathrm{b}-\mathrm{f}$ & -/gruri-k & 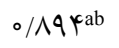 & $r / \mathcal{Y} \Delta^{\mathrm{ij}}$ & $r / \Delta Y^{b}$ & $\Delta \Delta / \wedge^{\mathrm{b}-\mathrm{h}}$ & $99 / 9^{\mathrm{a}-\mathrm{e}}$ & سيستان \\
\hline$\circ / Y \circ \varphi^{i-n}$ & - TQQqe-h & $\circ / D K{ }^{k}-\mathrm{m}$ & -NVG Y $Y^{d-g}$ & $T / Y Y^{\mathrm{i}-1}$ & $\varphi / \circ \Delta^{c d}$ & $M y / /^{k-m}$ & $\Delta V / T^{\mathrm{b}-\mathrm{g}}$ & نويد \\
\hline $0 / 1 / 4 p-r$ & $\circ / 19 \wedge^{\mathrm{m}-\mathrm{o}}$ & $\circ / 01 Y^{\operatorname{lm}}$ & $\circ / \Lambda 10^{b-f}$ & $r / / \mu^{j-n}$ & $r / r q^{f g}$ & r & $q \mu / \Delta^{a-f}$ & شعله \\
\hline$\circ / 00 q^{s}$ & $\circ / \circ 9 Q^{\mathrm{rs}}$ & $\circ / \mathcal{F} \wedge Y^{1 m}$ & $0 / 99 V^{g-i}$ & $\circ / 99 \circ 9$ & $T / \Lambda \Lambda^{\mathrm{i}-\mathrm{m}}$ & $\mu_{0} / \mu^{\mathrm{m}}$ & $01 / q^{e-j}$ & رختخم \\
\hline$\circ / Y_{\circ} \circ \mathrm{i}-\mathrm{n}$ & $\circ / Y \backslash V^{\mathrm{h}-\mathrm{m}}$ & $\circ / \Delta 0^{j-m}$ & 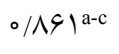 & $Y / \circ \wedge^{k-n}$ & $r / \circ V^{g h}$ & $\uparrow \& / 9 g-1$ & $V \pi / r^{a}$ & بيشتاز \\
\hline$\circ / T 90^{c-g}$ & $\circ /\left.\Gamma \Delta\right|^{a b}$ & o/grýli-k & -/AVYab & $T / T^{\mathrm{i}-1}$ & $r / r \varphi^{\text {fh }}$ & $\Delta r / T^{d-j}$ & $V V / T^{a}$ & جّمران \\
\hline $0 / Y Y I^{h-1}$ & $\circ / \mu q \circ a$ & $0 / 490 \mathrm{~m}$ & 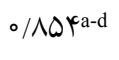 & $\Gamma / T \Delta^{\mathrm{i}-1}$ & $ץ / \Upsilon q^{f g}$ & $x / / \wedge^{\mathrm{h}-\mathrm{m}}$ & $G 4 / V^{\mathrm{a}-\mathrm{e}}$ & كرج \\
\hline$\circ / r_{0} \circ \mu^{\mathrm{i}-\mathrm{n}}$ & $0 / Y<q g-j$ & $\circ / 49 V^{l m}$ & - VDQ $q^{d-g}$ & $1 /\left.\Lambda\right|^{n-p}$ & $Y / T V^{i-1}$ & $\mathrm{~m} / \mathrm{D}^{\mathrm{k}-\mathrm{m}}$ & $V_{0} / \mathbb{q a b}^{\mathrm{a}}$ & بهار \\
\hline o/Iryo-r & $\circ / 199^{j-n}$ & o/Drrk-m & $\circ / V Y^{4} \wedge^{\mathrm{e}-\mathrm{g}}$ & $1 / \Lambda k^{\mathrm{rm}-\mathrm{p}}$ & r/q ch & $\hat{r} \circ / \varphi^{i-m}$ & $9 \wedge / \wedge^{\mathrm{a}-\mathrm{c}}$ & قدس \\
\hline$\circ / \circ q_{\circ} \mathrm{rs}$ & $\circ / 1 \circ \wedge^{q-s}$ & $\circ / \uparrow \Delta G^{m}$ & $\circ / V \circ V^{g-i}$ & $1 / 9 \circ p$ & $T / Q)^{i}$ & $r q / 0^{m}$ & $01 / q^{e-j}$ & 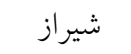 \\
\hline$\circ / 1 \circ \varphi^{\mathrm{rs}}$ & ०/IVGl-o & o/grVi-k & $\circ / \Lambda \mu^{\mathrm{b}-\mathrm{e}}$ & $1 / \Lambda k^{\mathrm{rm}-\mathrm{p}}$ & $T / \mathcal{K} \psi^{\mathrm{ij}}$ & $\mu_{\Lambda} / \Upsilon^{\mathrm{j}-\mathrm{m}}$ & $V_{0} / \varphi^{\mathrm{ab}}$ & كوير \\
\hline$\circ / \circ q$ rs & $\circ / / \Lambda^{\mathrm{o}-\mathrm{r}}$ & $0 / 49 \mathrm{Vlm}$ & $\circ / N M T^{f-h}$ & $1 / N^{\mu o p}$ & $r / /\left.\right|^{\text {gh }}$ & $\Gamma \wedge / \Delta^{\mathrm{m}}$ & $\uparrow \wedge / \Delta^{f-k}$ & الموت \\
\hline$\circ / 11 / 9 \mathrm{q}$ & $\circ / \mid Q \wedge^{n-q}$ & $0 / 9 \wedge q^{g-i}$ & $\circ / \Lambda V /^{a-c}$ & $r / / r^{j-n}$ & $r / \varphi_{0}$ ef & $r r / q \operatorname{lm}$ & $V Y^{\mathcal{A}} / \mathrm{V}^{\mathrm{a}}$ & تجن \\
\hline$\circ / T_{0} \circ Y^{i-n}$ & $\circ /\left.Y \&\right|^{\mathrm{d}-\mathrm{h}}$ & $\circ / \mathcal{G} \varphi_{0} \mathrm{~h}-\mathrm{j}$ & $\circ / 9 \circ \gamma^{a b}$ & $T / / Y^{j-n}$ & r/Vyde & $r q / \Delta^{i-m}$ & $V Y / \wedge^{\mathrm{a}}$ & خشكى 11 \\
\hline$\circ / / V_{0} 1-0$ & $\circ / \mu \circ \psi^{c-e}$ & $\circ /\left.9 \mu\right|^{\mathrm{i}-\mathrm{k}}$ & -/А৭ rab & $T / \Psi^{-1-k}$ & $\varphi / \wedge \Delta^{\mathrm{ab}}$ & $\Delta \psi^{\prime} / \mathcal{C}^{c-i}$ & $99 / 0^{\mathrm{a}-\mathrm{e}}$ & 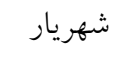 \\
\hline o/\人|k-o & $0 / Y Y^{c h} Y^{h-j}$ & $\circ / D<)^{k-m}$ & $\circ / \Lambda \mid Y^{b-f}$ & $r / /^{j-n}$ & $r / Y \Lambda^{f-h}$ & $|c| / V^{h-m}$ & $G Y / Y^{\mathrm{a}-\mathrm{e}}$ & كارون \\
\hline$\circ / T \circ \Delta^{i-n}$ & $\circ /\left.T Q\right|^{f-i}$ & $\circ / \Delta \Delta q^{j-1}$ & $\circ / \mathrm{V} V V^{\mathrm{c}-\mathrm{g}}$ & $Y / \circ q^{k-n}$ & $r / 9 \Lambda^{e}$ & $\mid \mathrm{f} / /^{\mathrm{h}} \mathrm{h}-\mathrm{m}$ & $V \psi / 0^{a}$ & گَاسيارود \\
\hline $0 / 19 \psi^{q n}-p$ & o/ & $\circ / 91 Y^{\mathrm{i}-\mathrm{k}}$ & $\circ / \Lambda T Y b-f$ & $r / \circ Y^{1-0}$ & $r / 9 \Lambda^{e}$ & $\mathrm{r} \mathrm{\omega} / \mathrm{T}^{\mathrm{k}-\mathrm{m}}$ & $q \Lambda /\left.\right|^{4 a-c}$ & اميد \\
\hline $0 / Y \ll r^{h-j}$ & $\circ / \mu \mid Y^{b-d}$ & $0 / 991^{g-i}$ & o/VQYe-g & $T / Y Y^{\mathrm{i}-1}$ & $\varphi / 19^{\circ}$ & $\varphi_{\circ} / \gamma^{i-m}$ & $V Y / v^{a}$ & مرودشت \\
\hline
\end{tabular}

براى هر صفت تفاوت بين ميانخينهايى كه حداقل داراى يك حرف مشترى هستند، براساس آزمون LSD در سطح احتمال ينج

مطالعه لويز و همكاران، تــش شـورى باعـث افـزايش غلظـت كاروتنوئيد در جو شد (YN).

تأثير افزايش غلظت دىاكسيد كربن بر غلظت كلروفيـل a و

b و غلظت كاروتنوئيد در سطح احتمال يك درصد معنىدار بود (جـــول (). غلظـت كلروفيـل a كلروفيـل b و كاروتنوئيــ در شرايط غنى شده دىاكسيد كربن در مقايسه با غلظت معمول آن آ آزمايش قادرى و همكاران در اثر غنى سازى غلظــت دىاكسـيد كربن محيط تا سطح مo ميكرومول بر مول غلظت كلروفيـل و b در كلزا افزايش يافـت (ro). در آزمـايش كـاظمى بـر روى

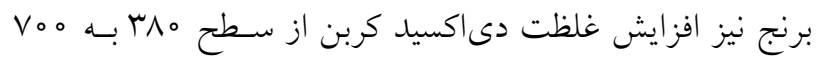

سطح احتمال يـك درصــ معنسى دار شــ (جـــول (). غلظـت

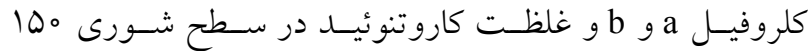

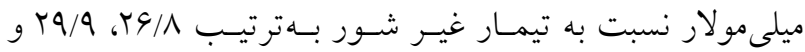
ro/D درصد كاهش يافت (جدول Y). در آزمايش فرهودى نيـز تنش شـورى معـادل ه | ا ميلسى مـولار سـبب كـاهش معنسى دار

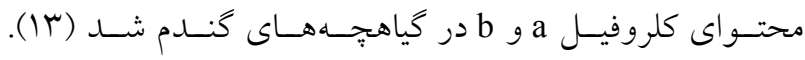
اميرجانى كزارش كرد كه محتواى كلروفيل b در سـطح شـورى

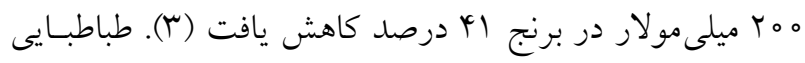
و احسانزاده نيز كـزارش كردنـــ كـهـ شـورى •ها ميلـى مـولار كلريد سديم سبب كاهش غلظـت كاروتنوئيـدها در كنــمهــاى تتر إيلوئيسـا يوشـينهدار و دوروم مسىشـود (YY)، درحسالى كـه در 
جدول ^ـ برهمكنش اثر دىاكسيد كربن و رقم بر غلظت يتاسيم اندام هوايى، نسبت بتاسيم به سديم اندام هوايى، كلروفيل

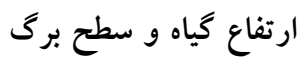

\begin{tabular}{|c|c|c|c|c|c|c|c|c|c|c|}
\hline \multicolumn{2}{|c|}{ سطح برى } & \multicolumn{2}{|c|}{ ارتفاع گياه } & \multicolumn{2}{|c|}{ كلروفيل b } & \multicolumn{2}{|c|}{ سديمبت اندام هويم بـ به } & \multicolumn{2}{|c|}{ انداًّم هوائى } & \multirow{2}{*}{ ارقام گندم } \\
\hline Voo & ऍ人。 & Voo & r人。 & Voo & $r \wedge 。$ & Voo & rı。 & Voo & r & \\
\hline$G Y / \mathbb{C a}^{\mathrm{a}-\mathrm{c}}$ & $\Delta V / q^{a-e}$ & $q 1 / \mu^{a}$ & $\Delta \circ / \Delta^{d-k}$ & $\circ / \mu 11^{a}$ & $\circ / Y \wedge V^{a b}$ & $1 / 4 a^{a}$ & $1 / T \Delta^{d}$ & $0 / T_{9} Y^{a-c}$ & $0 / T \& \Delta^{\mathrm{a}-\mathrm{g}}$ & سياهان \\
\hline$G Y / \mu^{a-c}$ & $\Delta \wedge / \Delta^{\mathrm{a}-\mathrm{e}}$ & $91 / \mathrm{T}^{\mathrm{a}}$ & $\mathrm{rq} / \circ^{\mathrm{g}-1}$ & $\circ / \mu 1 \circ a$ & $\circ /$ YAVab & $1 / 4 \circ b$ & $1 / / \circ j k$ & $0 /$ rquab & $\circ / T \Delta V^{a-i}$ & سيستان \\
\hline$Y \wedge / 0^{c-i}$ & $k r / \varphi^{e-i}$ & $\Delta 9 / /^{b-c}$ & $\mu \psi / \Lambda^{1-p}$ & $\circ / Y \mid V^{c-h}$ & $0 / I V \wedge^{\mathrm{g}-\mathrm{l}}$ & $1 / Y_{0}$ ef & $\circ / 9 \wedge / \mathrm{mn}$ & o/ TצY & $\circ / T r Q^{d-j}$ & نويد \\
\hline$\Delta r / \Gamma^{b-g}$ & $\mathrm{~F} / \mathrm{A}^{\mathrm{c}-\mathrm{i}}$ & $F V / o^{j-n}$ & $r q / \circ q$ & $\circ / \backslash \wedge \mathrm{r}^{\mathrm{f}-1}$ & $\circ / \backslash Q \Delta^{\mathrm{j}-\mathrm{m}}$ & $1 / T \Delta^{d}$ & $1 / r l^{\mathrm{e}}$ & $\circ /\left.Y Q\right|^{a-j}$ & $\circ / T \wedge \circ \mathrm{a}-\mathrm{d}$ & شعله \\
\hline$\varphi \Delta / \varphi^{d-i}$ & $\hat{r} \circ / \Delta^{\mathrm{g}-\mathrm{i}}$ & $\uparrow q / \varphi^{f-1}$ & $|q| / \wedge^{o-q}$ & $0 / / r^{k-m}$ & $\circ / 1 \circ 4^{m}$ & $\circ / 90 / 9 \mathrm{rr}$ & $\circ / \wedge \circ \circ u$ & $0 / T r Q^{\mathrm{e}-\mathrm{j}}$ & $\circ / Y^{\prime} V^{\mathrm{ij}}$ & \\
\hline$G r / V^{a-c}$ & $\Delta V / \varphi^{a-e}$ & $01 / \wedge^{\mathrm{c}-\mathrm{i}}$ & $\mathrm{rr}^{\mathrm{r}} / \mathrm{V}^{\mathrm{m}-\mathrm{q}}$ & $0 / \pi \mu_{0} c-f$ & $\circ / Y \circ \circ d-j$ & $1 / 10^{g-i}$ & $\circ / 9 \mu^{\mu} \wedge^{o p}$ & $0 /$ Yyka-j & $\circ / Y_{\circ} \mathcal{G}^{\mathrm{ij}}$ & بيشتاز \\
\hline $9 \wedge N^{\mathrm{a}}$ & $q \mu / r^{\mathrm{ab}}$ & $\Delta Y / q b-e$ & $\hat{q} V / q^{i-m}$ & o/ YY $\Delta^{b-\mathrm{d}}$ & $\circ / Y_{0} \gamma^{d-j}$ & $1 / 4$ rab & $1 / \circ V^{k l}$ & $\circ / Y \wedge \circ \mathrm{a}-\mathrm{d}$ & •/Tr $\Delta^{d-j}$ & جُمر ان \\
\hline$\Delta Q / V^{a-f}$ & $\Delta \circ / \wedge^{b-i}$ & $\hat{\varphi} \wedge / \varphi^{\mathrm{h}-1}$ & $\varphi \backslash / \wedge^{o-q}$ & $\circ / Y \circ \varphi^{d-j}$ & $\circ /\left.I V\right|^{h-1}$ & $1 / 1 Y^{i j}$ & $0 / 94 q \mathrm{pq}$ & $0 /\left.Y^{\prime}\right|^{\mathrm{a}-\mathrm{j}}$ & $0 / T^{\prime \mu g-j}$ & كرج \\
\hline$\Delta \psi / V^{a-g}$ & $<q / Y^{b-i}$ & $\Delta Y / o^{b-f}$ & $\mathrm{qr} / \mathrm{om}^{\mathrm{m}-\mathrm{q}}$ & $\circ / T_{\circ} \varphi^{d-j}$ & $\circ / / V_{0}{ }^{h-1}$ & $1 / 1 \Lambda^{\mathrm{e}-\mathrm{g}}$ & $1 / 0 \circ \mathrm{m}$ & o/Trqa-j & $\circ / T \mu_{0} d-j$ & بهار \\
\hline$\Delta V / o^{a-e}$ & $\Delta r / N^{b-g}$ & $\Delta r / \wedge^{b-f}$ & $\varphi \Delta / \varphi^{l-p}$ & $\circ /\left.T \backslash\right|^{\mathrm{d}-\mathrm{i}}$ & $\circ /|V|^{h-1}$ & $1 / 041$ & $1 / I V^{f-h}$ & $O /\left.Y Y\right|^{a-j}$ & $0 / r \& q^{a-f}$ & قدس \\
\hline $41 / 0^{\mathrm{f}-\mathrm{i}}$ & $r G / \wedge^{h i}$ & $\Delta \circ / V^{d-k}$ & $Y r / \wedge^{n-q}$ & $\circ / \backslash \Delta q^{j-1}$ & Irm & 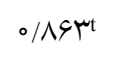 & $\circ / V Q \Lambda^{v}$ & $0 / T \backslash \Lambda^{f-j}$ & $\circ / 199^{j}$ & شيراز \\
\hline$\Delta V / T^{a-e}$ & $01 / 4 b-h$ & $\Delta r / \wedge^{b-f}$ & $p</ q^{1-p}$ & $\circ / \backslash \wedge f^{f-1}$ & $\circ / \mid q \mu^{\mathrm{i}-1}$ & $1 / I V^{f-h}$ & $\circ / 94 \wedge^{\text {no }}$ & $o / T Y V^{a-j}$ & $\circ / T Y V^{d-j}$ & كوير \\
\hline$f \mid / r^{f-i}$ & $r \Delta / q^{i}$ & $0 \circ / Y^{e-k}$ & $\hat{q} / \circ \mathrm{om}-\mathrm{q}$ & $\circ / I V r^{\mathrm{h}-1}$ & $0 / / k 4 k-m$ & $\circ / \wedge 9 \Delta^{r s}$ & $\circ / V Q \circ v$ & $\circ / T \mid V^{f-j}$ &.$/ 199^{j}$ & الموت \\
\hline$\Delta \varphi / \Delta^{\mathrm{a}-\mathrm{e}}$ & $01 / 1^{b-h}$ & $\mathrm{cr}^{\mathrm{r}} / \mathrm{r}^{\mathrm{m}-\mathrm{q}}$ & $\varphi \circ / q p q$ & $0 / T H Y^{c-f}$ & $\circ / \backslash \wedge \Lambda^{\mathrm{e}-\mathrm{k}}$ & $1 / I V^{f-h}$ & $1 / / r^{\mathrm{ij}}$ & o/TGYa-h & $\circ / T V Q^{\mathrm{a}-\mathrm{e}}$ & \\
\hline$\Delta \wedge / q^{a-d}$ & $\Delta r / \varphi^{a-g}$ & $\Delta Q / o^{b-d}$ & $\varphi \Leftrightarrow / \wedge^{\mathrm{k}-\mathrm{n}}$ & $\circ / \Upsilon \wedge V^{a b}$ & $\circ / Y \circ \varphi^{c d-j}$ & $1 / \circ V^{k l}$ & $\circ / \wedge ९ Q^{s t}$ & $\circ / T r \Delta^{d-j}$ & $\circ / T\}^{g-j}$ & خشكى 11 \\
\hline$\Delta Q / 0^{a-d}$ & $91 / 4 a-c$ & $\Delta Y / q^{b-h}$ & $01 / 9^{c-j}$ & $\circ / Y Y^{b-e}$ & $\circ / Y Y_{\circ} \mathrm{c}-\mathrm{h}$ & $1 /\left.4\right|^{b}$ & $1 / / y^{h i}$ & $\circ / \Upsilon 90^{\mathrm{a}}$ & $\circ / r \Delta r^{a-j}$ & شهريار \\
\hline$\Delta Q / /^{\mathrm{a}-\mathrm{g}}$ & $\Delta \circ / \wedge^{b-i}$ & $\Delta r / 4 b-g$ & $p \psi / q^{l-p}$ & $0 / T Y q^{c-g}$ & $0 / 19 V^{d-j}$ & $1 / 19^{\mathrm{gh}}$ & $0 / \Lambda g \mu^{t}$ & $0 / Y Y<\left.\right|^{a-j}$ & $\circ / Y \circ \Lambda^{h-j}$ & كارون \\
\hline $90 / 0^{a-d}$ & $\Delta \& / \mu^{a-g}$ & $\Delta r / T^{b-h}$ & $\varphi \varphi / \mu^{\mathrm{k}-\mathrm{o}}$ & o/Yrab-e & $\circ / 199^{d-j}$ & $1 / \circ \wedge^{k}$ & $1 / \circ V^{k l}$ & $0 / T \mu \Lambda^{c-j}$ & $\circ / T \varphi Q^{a-g}$ & كاسيارود \\
\hline$\Delta Y / Y^{b-g}$ & $01 /{ }^{\mathrm{b}-h}$ & $\Delta r / q^{b-h}$ & $p \psi / q 1-p$ & $\circ / Y Y \circ b-d$ & $\circ / Y \circ \varphi^{d-j}$ & $1 / \mu_{\circ} c$ & $1 / 041$ & $\circ / T \wedge \circ \mathrm{a}-\mathrm{d}$ & $\circ / Y Y Q^{a-j}$ & اميد \\
\hline$\Delta Q / \Delta^{a-d}$ & $\Delta \Delta / \varphi^{a-g}$ & $\Delta V / Y^{\mathrm{ab}}$ & $\varphi \Leftrightarrow / V^{k-n}$ & o/rgra-c & $\circ / Y \backslash \wedge^{\mathrm{c}-\mathrm{h}}$ & $1 / T G d$ & $1 / \circ V^{k l}$ & $\circ / T V T^{\text {a-e }}$ & $\circ / T Y_{\circ} \circ-j$ & مرودشت \\
\hline
\end{tabular}

براى هر صفت، تفاوت بين ميانكينهايى كه حداقل داراى يك حـرف مشـترى هسـتند، براسـاس آزمـون LSD در سـطح احتمـال يــنج درصــ معنى دار نيست.

تأثير برهمكنش اثرات شورى و غلظت دىاكسيد كربن بـر غلظت كلروفيل b در سطح احتمـال يـك درصـــ و بــر غلظـــ كلروفيل a و غلظت كاروتنوئيد، در سطح احتمـال يـنج درصــ معنى دار بـود (جــول (). در اثـر افز ايش غلظـت دىاكسيد كربن غلظت كلروفيـل a و b و غلظـت كاروتنوئيــــ در شـرايط غيـر شـور

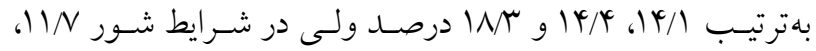

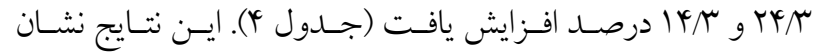

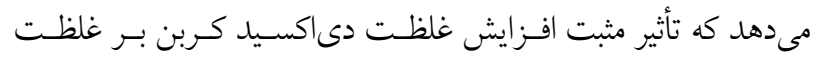
كلروفيل a و كاروتنوئيد در شرايط غير شور ولى بر غلظـت كلروفيـل

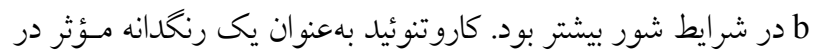
مقاومت به تنشها، در شرايط شورى بهطورمعمول افـزيش مسيابـــ
ميكرومــول بــر مــول، باعـث افـزايش ها درصـــى غلظــت

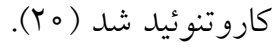
تفاوت ارقام مورد مطالعه از نظر غلظت كلروفيل b در سطح

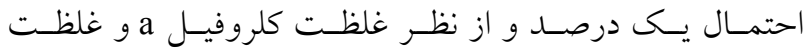
كاروتنوئيد در سطح احتمال ينج درصد معنى دار بود (جدول (1). بيشترين و كمترين غلظت كلروفيل a بهترتيب به ارقـام شهـريار

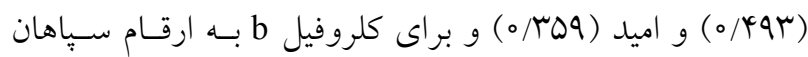

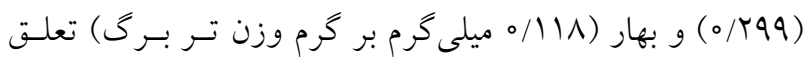

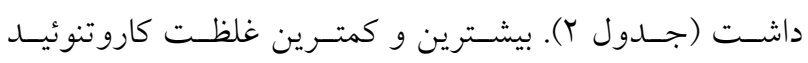

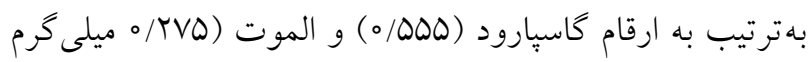
بر گرم وزن تر برگ) تعلق داشت. 
سطح برى كاهش مى يابد. كاهش سطح بـرى در شـر ايط شـور

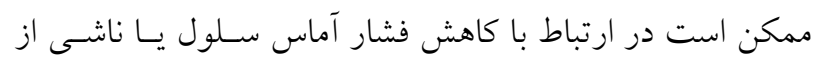

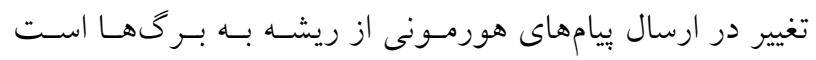

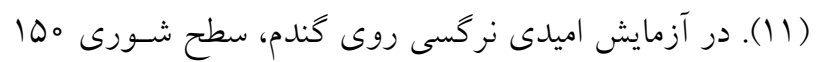

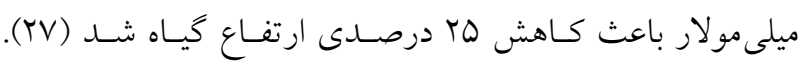

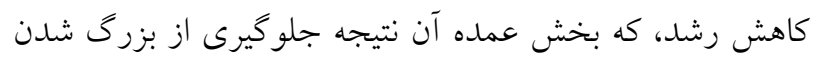

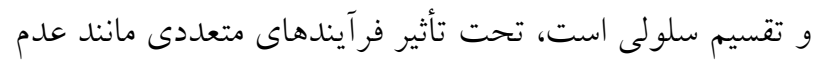

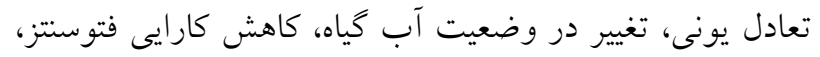
اختلال در جذب عناصر و اختلال در جذب، احياء و متابوليسم نهم

نيتروزن و يروتئين است (19).

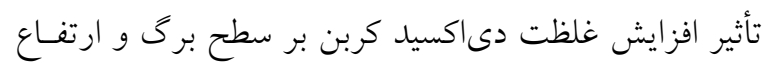

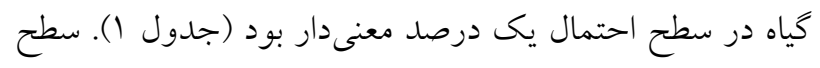
برگ و ارتفاع گياه در شرايط غنى شده غلظت دى اكسيد كـربن

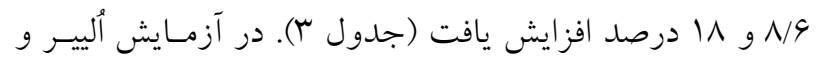

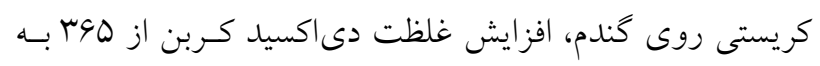

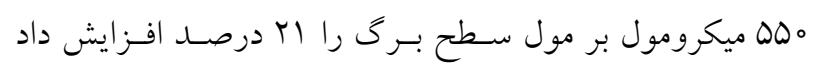

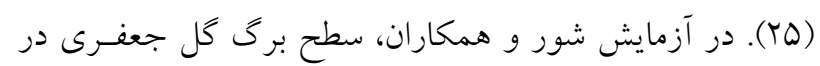

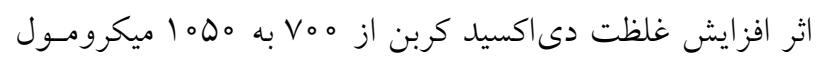

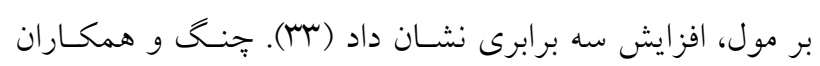

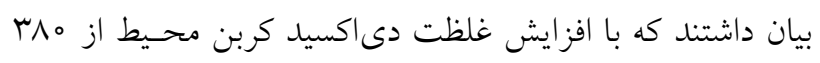

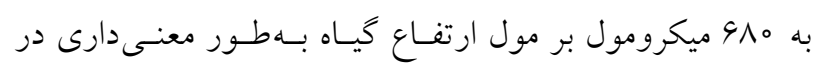
بوتههاى برنج افزايش مىيابد (م).

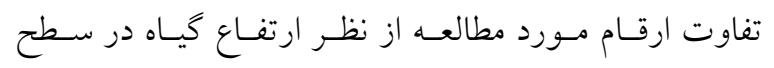
احتمال يك درصد و از نظر سطح برى در سـطح احتمـال يـنج

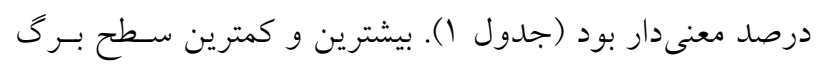

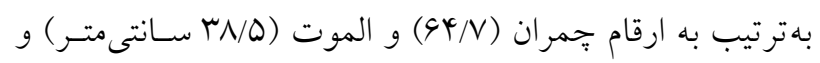
بيشترين و كمترين ارتفاع كياه به ارقام سـياهان (هQ/Q) و و تجسن

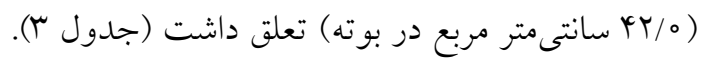

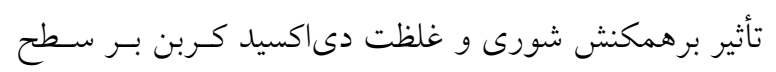

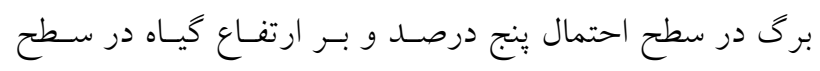

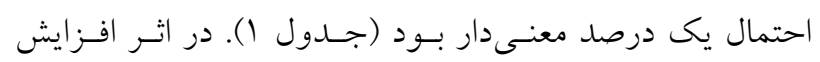

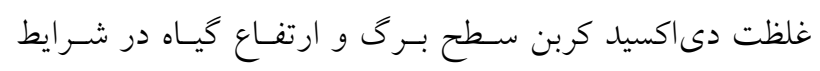

(YY) با اين حال، توليد اين ماده نياز به انرزى نسبتاً بـالايى دارد و لـــا

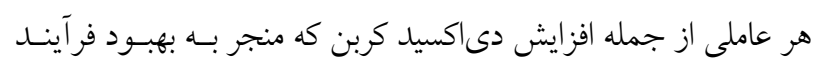

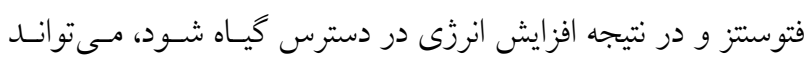

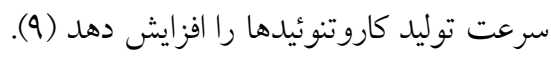

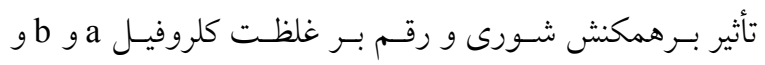

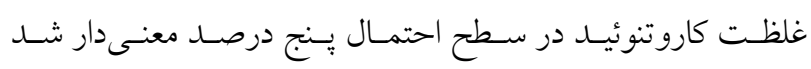

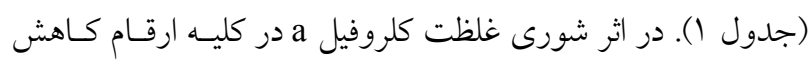

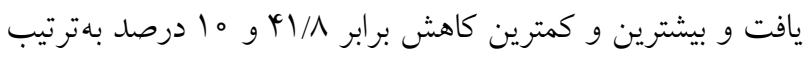

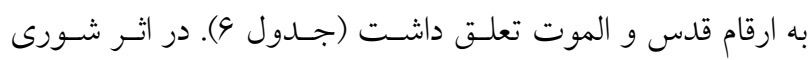

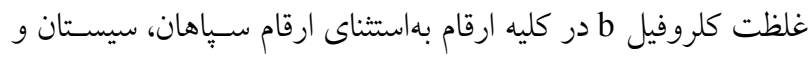

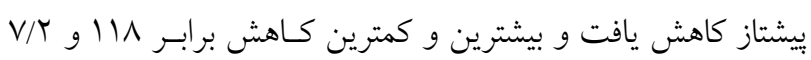
درصد به ارقام سرختخم و كوير تعلـق داشـت. در ارقـام سـياهان،

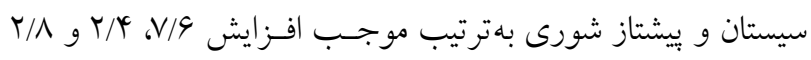
درصدى غلظت كلروفيل b شد. در اثر شـورى غلظـت كاروتنوئيـد

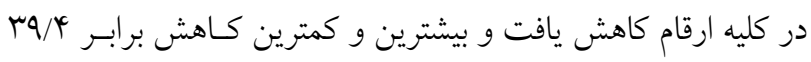

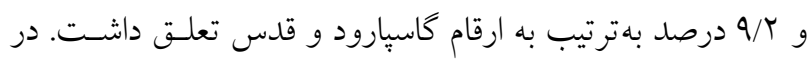

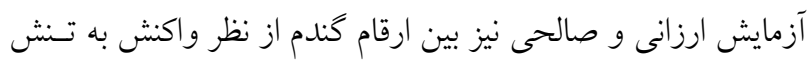

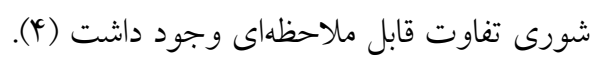

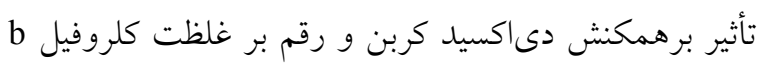

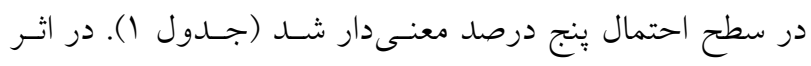
افزايش غلظت دىاكسيد كربن غلظت كلروفيل b در كليه ارقـام

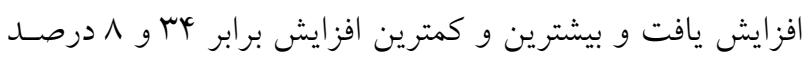
بهترتيب به ارقام سرختخم و سيستان تعلق داشت (جدول م).

\section{سطح برى و ارتفاع گياه}

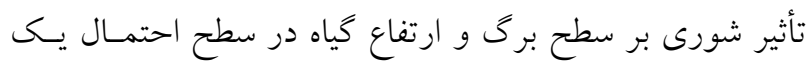

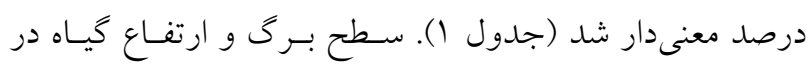

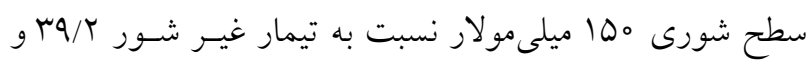

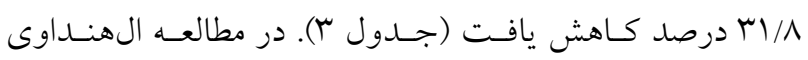

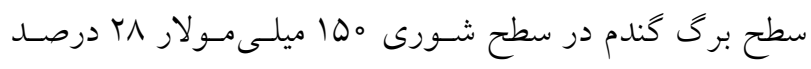

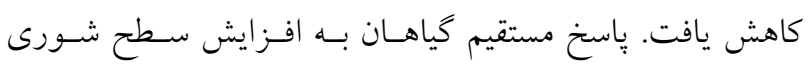

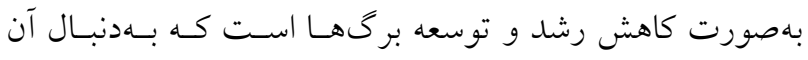


ارقام بهار و شهريار تعلق داشت.

حجم ريشه تأثير شورى بر حجم ريشه در سطح احتمال يكى درصد معنى دار شد (جدول (). حجم ريشه در سطح شـورى 100 ميلسى مـولار

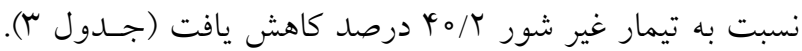

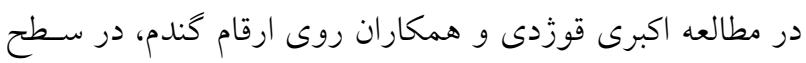

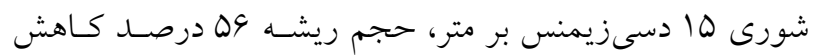

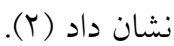

تأثير افزايش غلظت دىاكسيد كربن بر حجم ريشه در سطح احتمال يكى درصد معنى دار بـود (جــول (). حجـم ريشـه در

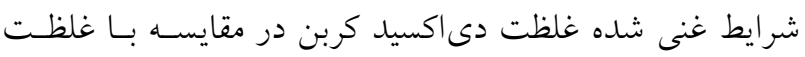

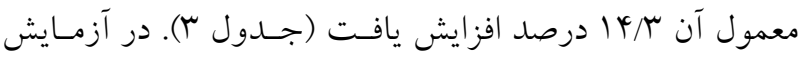

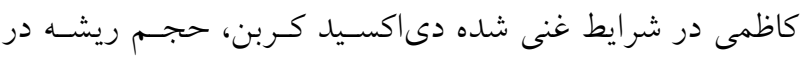

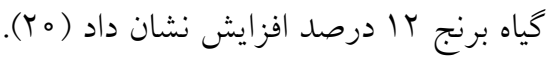
تفاوت ارقام مـورد مطالعهـ از نظـر حجـم ريشـه در سطح احتمال يك درصد معنى دار بود (جدول (). بيشترين و كمتـرين

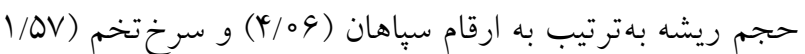

سانتىمتر مكعب در بوته) تعلق داشت (جدول مَ).

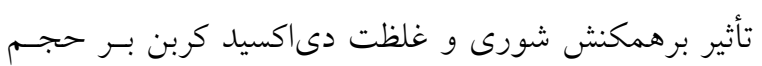
ريشه در سطح احتمال يك درصد معنىدار بود (جـدول ()). در اثر افزايش غلظت دىاكسيد كربن حجم ريشهه در شـرايط غيـر شور 19 و در شرايط شور (9/1 درصد كاهش يافت (جــدول \&).

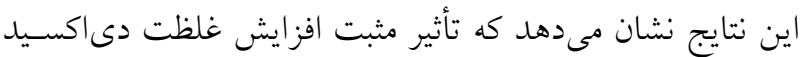
كربن بر حجم ريشه در شرايط غير شور بيشتر بوده است. تأثير برهمكنش شـورى و رقـم بـر حجـم ريشـه در سطح

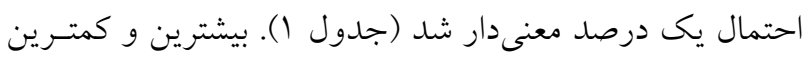

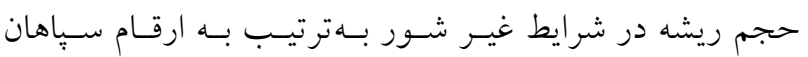

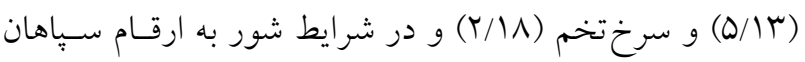

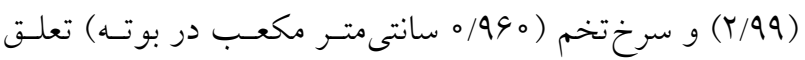
داشت (جدول V). در اثر شـورى حجـم ريشـهـ در كليـه ارقـام

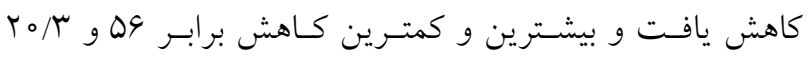

غيرشور بهترتيـب 9/1 و 9/9 و در شـرايط شـور 1/9/9 و 4/9

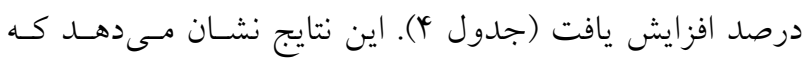

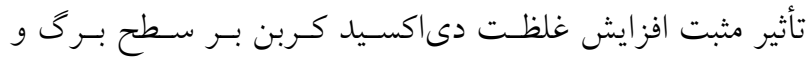

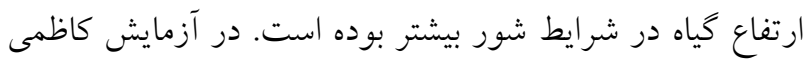

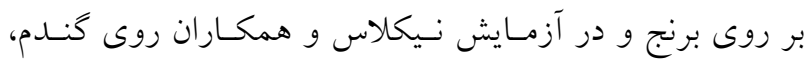

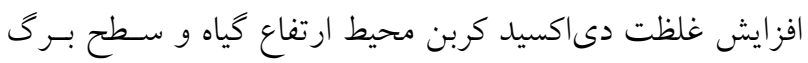
را در شرايط شور در مقايسـه بـا شـرايط غيـر شـور بـه نسـبت

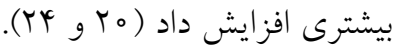
تأثير برهمكنش شورى و رقم بر سطح برى و ارتفـاع گيـاه

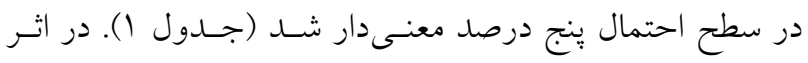

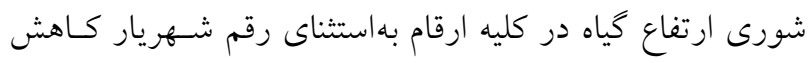

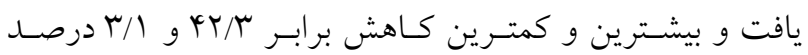

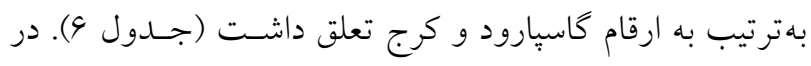

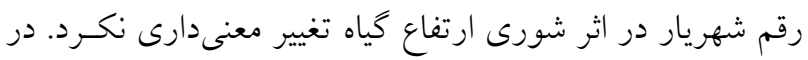

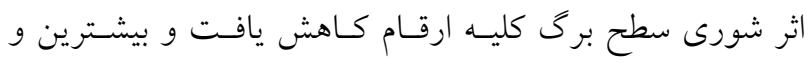
كمترين كاهش برابر ه9 و 19/9 درصد به به ارقام تجن و سيستستان

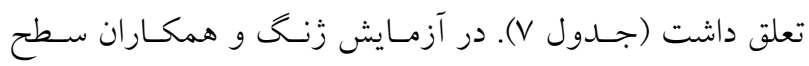

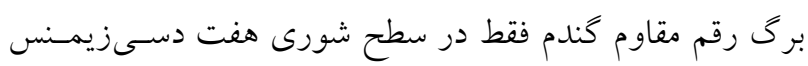
بر متر كاهش يافت و در سطوح شورى سه و ينج دسىزيمـسنس

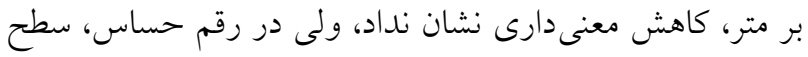

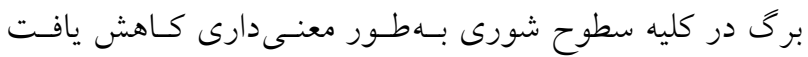

تأثير برهمكنش غلظت دىاكسيد كربن و رقم بر سطح برى در سطح احتمال يك درصد و بر ارتفاع گياه در سـطح احتمـال

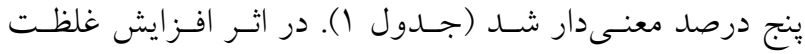
دى اكسيد كربن، سطح برى در كليـه ارقـام بـهاسـتنثاى شـهريار

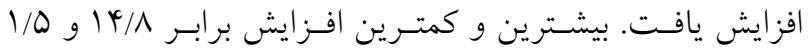
درصــــــه ارقـام المـوت و اميـــ تعلـق داشـت (جـــول م).

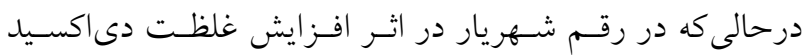

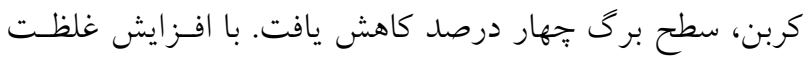

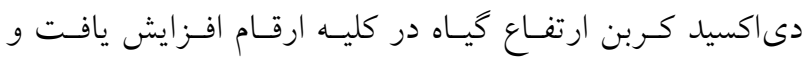

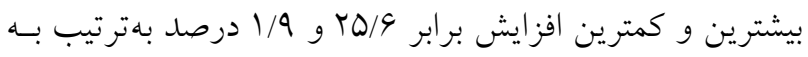




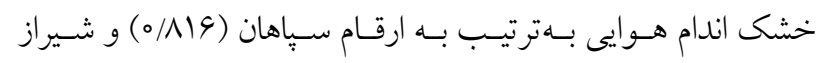

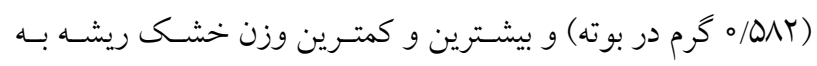

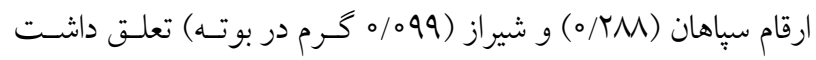

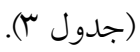

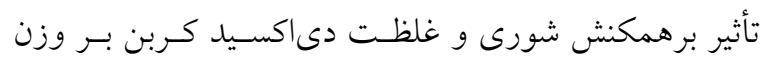
خشى ريشه در سطح احتمال يك درصد و بر وزن خشى هـى اندام هوايى در سطح احتمال ينج درصد معنىدار بود (جــدول (). در

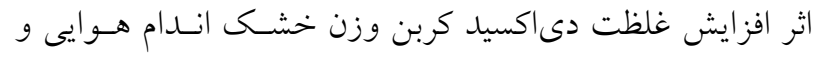

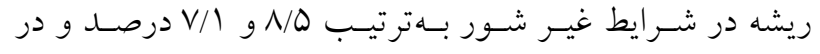
شرايط شور بهترتيب 19/1 و 1/0/0 درصد افزايش يافت (جدول

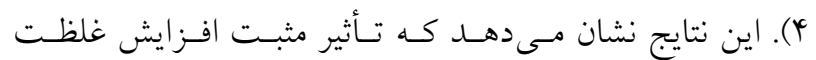
دى اكسيد كربن بر وزن خشـك انــام هـوايى در شـرايط شـور

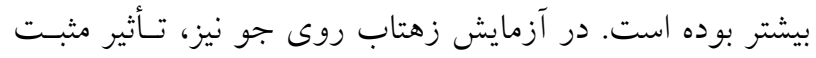

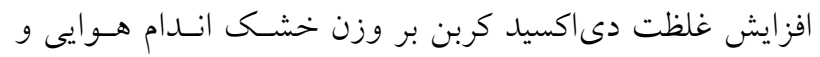
ريشه در شرايط شور بيشتر بود (ه山).

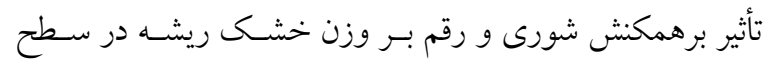
احتمال يكى درصد و بر وزن خشك اندام هـوايى در سـطح احتمـال

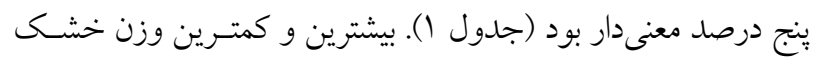

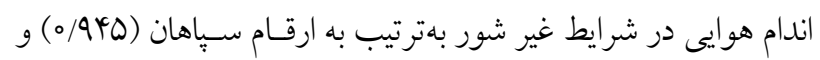

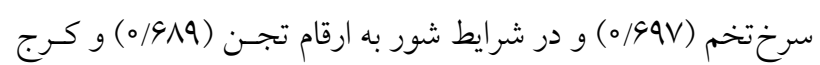

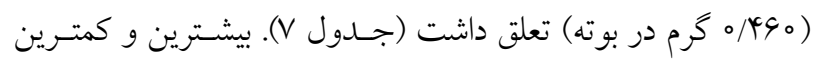
وزن خشك ريشه در شـر ايط غيــ شـور بـهـترتيـب بـه ارقـام كرج

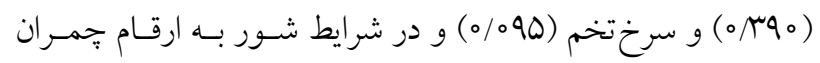

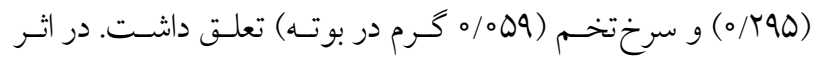
شورى وزن خشك اندام هوايى و ريشه در كليه ارقام كـاهش يافـت.

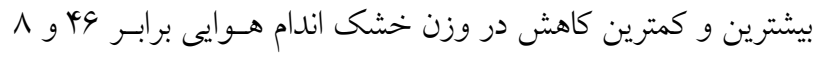

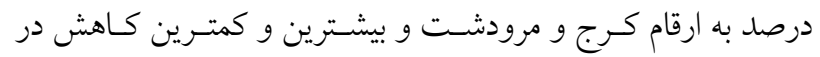

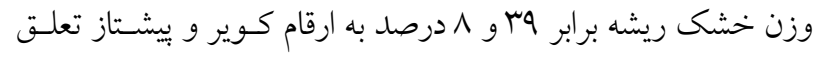
داشت. با توجه به اينكه مقاومت ارقام به شرايط تنش با ميزان كـاهش در ماده خشك توليدى سنجيده مىشود، بهنظـ مسىرســ در شـرايط اين آزمايش، رقم مرودشت در مقايسه با ديخر ارقـام مـورد مطالعهـ از مقاومت نسبى بالاترى به تنش شورى برخوردار است.
درصد متعلق به ارقام سرختخم و بهار بود.

\section{وزن خشك اندام هوايى و ريشه}

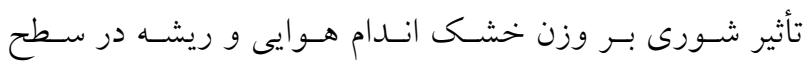
احتمال يك درصد معنىدار شد (جدول (). وزن خشــ انــام

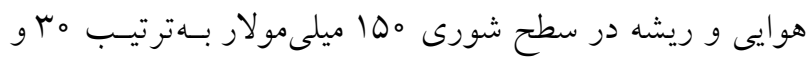

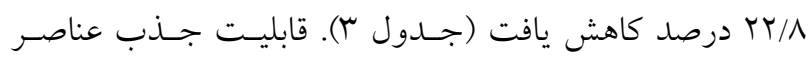

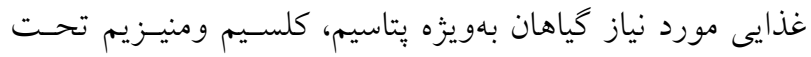

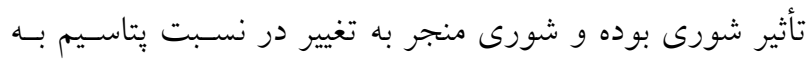

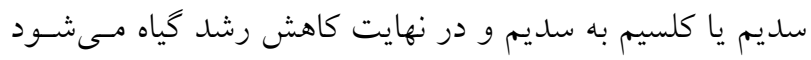
(11). در مطالعه حاضر نيز تنش شورى بهواسطه تغيير در تعادل

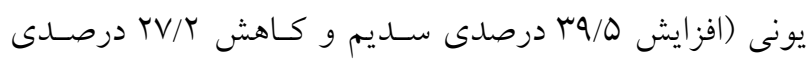

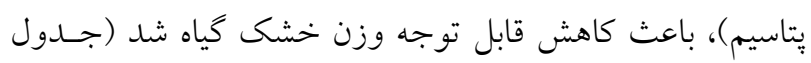

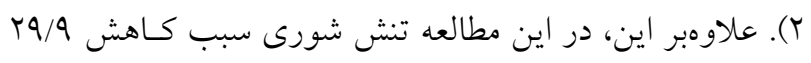

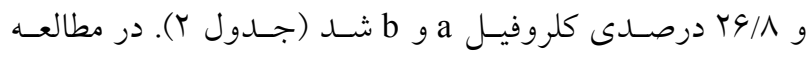

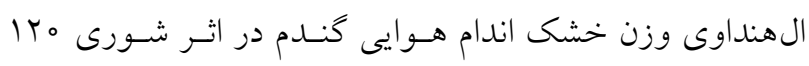

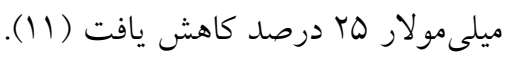

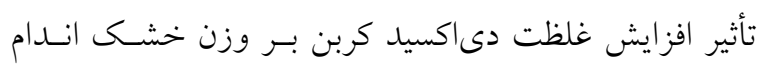

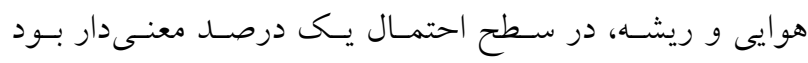

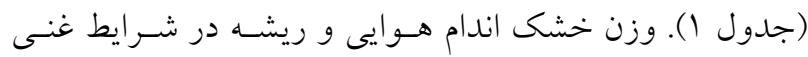

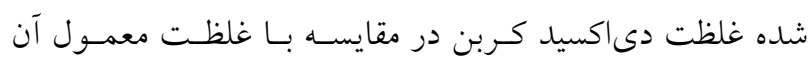

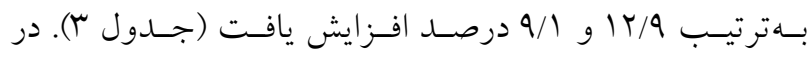
آزمايش هكى و همكاران روى كُندم، افزايش غلظت دى اكسيد

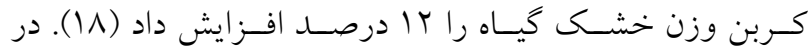
مطالعه حاضر افزايش غلظت دى اكسيد كربن بهواسطه كاهش 1 مرن درصدى غلظت سديم و افزايش V/V درصـدى غلظـت بت بتاسـيم

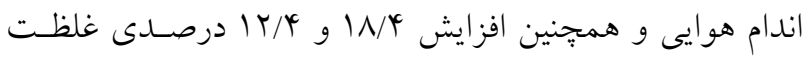

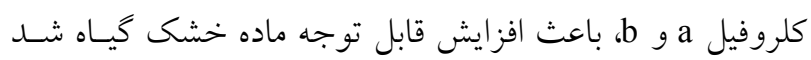

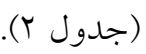
تفاوت ارقام مورد مطالعـهـ از نظــــ وزن خشـك انــام هـوايى در

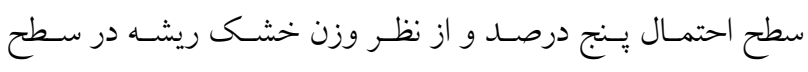

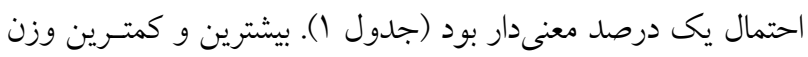


جدول 9. برهمكنش اثر دىاكسيد كربن و رقم بر وزن خشك اندام هوايى و ريشه (كرم در بوته)

\begin{tabular}{|c|c|c|c|c|}
\hline \multicolumn{2}{|c|}{ وزن خشك ريشه } & \multicolumn{2}{|c|}{ وزن خشك اندامهوايى } & \multirow{2}{*}{ ارقام گُندم } \\
\hline Voo & r人。 & Voo & r人。 & \\
\hline$\circ / \Gamma I V a b$ & $\circ / r \Delta q^{d-h}$ & $\circ / \Lambda Y^{\mathrm{r}} \wedge^{\mathrm{bc}}$ & $\circ /$ VAYb-e & سياهان \\
\hline$\circ / T V \Delta^{b-f}$ & $0 /$ YGYc-g & $\circ / \mathrm{NA})^{\mathrm{b}-\mathrm{f}}$ & $\circ / N \& q^{d-g}$ & سيستان \\
\hline o/TrVe-j & $0 / Y Y \varphi^{\mathrm{f}-\mathrm{k}}$ & $0 / 9 \wedge \Lambda^{\mathrm{f}-1}$ & $0 / 91 V^{k-o}$ & نويد \\
\hline$\circ / 10 \circ \mathrm{m}-\mathrm{p}$ & o/Mro-r & $\circ /\left.\mathrm{V} \circ\right|^{\mathrm{e}-\mathrm{k}}$ & $0 / 9 Y^{\mathrm{j}-0}$ & شعله \\
\hline$\circ / \circ \wedge \uparrow^{\mathrm{rs}}$ & $\circ / \circ V^{\mathrm{s}}$ & $0 / 91 V^{k-o}$ & ०/DGYno & رخختم \\
\hline$\circ /\left.T \backslash\right|^{\mathrm{h}-\mathrm{k}}$ & $\circ / Y \circ \varphi^{\mathrm{i}-1}$ & $\circ / V 9 \Delta^{c-f}$ & - $9 y<$ h-o & ي بيشتاز \\
\hline$\circ / \mu q^{a}$ & $\circ / \mathrm{V} \mathrm{Vab}$ & $\circ / 9 V / a$ & o/9rqi-o & "جمران \\
\hline$\circ / T \& V^{b-g}$ & $0 /$ Tfff-k & ./Nrrd-h & $\circ / \mathrm{\Delta} \wedge 0^{\mathrm{m}-\mathrm{o}}$ & كرج \\
\hline (TMTe-j & $\circ / Y Y \circ g-k$ & $\circ / 990 \mathrm{~g}-\mathrm{m}$ & $\circ / 09)^{\mathrm{m}-\mathrm{o}}$ & بهار - ار \\
\hline$\circ / I V V^{k-o}$ & ०/ $\Delta\}^{1-p}$ & $\circ / 9 \wedge V^{f-1}$ & $\circ / 9 \circ \mu^{1-0}$ & ق ق قدس \\
\hline$\circ / 1 \circ \Delta^{p-s}$ & $\circ / \circ q 4 q-s$ & $\circ / 9 \mid Y^{\mathrm{k}-\mathrm{o}}$ & $\circ / \Delta \Delta 1^{\circ}$ & 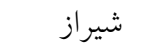 \\
\hline $0 / /$ frn-q & $\circ / \Lambda V^{n-q}$ & $\circ / V Q \circ d-g$ & $\circ / V \backslash \varphi^{d-j}$ & كوير \\
\hline$\circ / / \mathrm{Vp}-\mathrm{s}$ & $\circ / / 1 \mathrm{Q}^{\mathrm{p}-\mathrm{s}}$ & $0 / 919^{k-o}$ & $\circ /\left.\Delta \wedge\right|^{\mathrm{m}-\mathrm{o}}$ & الموت \\
\hline$\circ / / \varphi Q^{\mathrm{n}-\mathrm{q}}$ & $0 / / Y \mu p-r$ & $\circ / \Lambda V^{b}$ & $0 / 99 \circ \mathrm{e}-1$ & تجن \\
\hline$\circ / T M \Delta^{e-j}$ & $\circ / Y \gamma^{\mathrm{f}-\mathrm{k}}$ & $\circ / \wedge \circ q^{b-d}$ & $\circ / V r \Delta^{d-h}$ & خشكى 11 \\
\hline$\circ /\left.Y q\right|^{a-d}$ & $\circ / T \wedge r^{a-e}$ & $\circ / \mathrm{V} \wedge \circ \mathrm{b}-\mathrm{f}$ & o/vfyd-g & شهريار \\
\hline $0 /$ TrMg-k & $\circ / Y \circ \circ \mathrm{i}-\mathrm{m}$ & $\circ / \mathrm{V} \circ \varphi^{\mathrm{e}-\mathrm{k}}$ & $0 / 9 \% V^{\mathrm{h}-\mathrm{n}}$ & كارون \\
\hline o/TrVe-j & $0 / T \backslash \wedge \wedge^{\mathrm{g}-\mathrm{k}}$ & o/VYYd-i & $0 / 91 Y^{\mathrm{k}-\mathrm{o}}$ & كاسيارود \\
\hline$\circ / \Gamma \circ \Lambda^{\mathrm{h}-\mathrm{k}}$ & $\circ / \backslash \wedge \vee^{j-n}$ & $\circ / N{ }^{\mu}{ }^{d-h}$ & $\circ / V \circ \circ \mathrm{e}-\mathrm{k}$ & اميد \\
\hline$\circ / N \backslash \|^{a-c}$ & $\circ / T Y \Delta^{\mathrm{d}-\mathrm{i}}$ & $\circ / V \mu Y^{d-h}$ & $0 / 991 \mathrm{~g}-\mathrm{m}$ & مرودشت \\
\hline
\end{tabular}

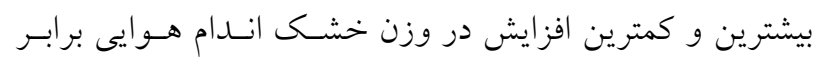

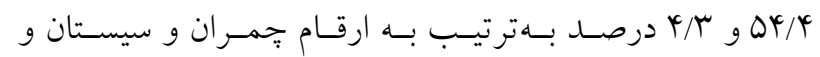
بيشترين و كمترين افزايش در وزن خشك ريشـهـ برابـر Y Y و و

ا درصد بهترتيب به ارقام مرودشت و الموت تعلق داشت.

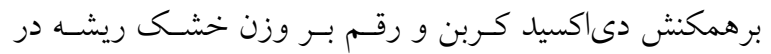

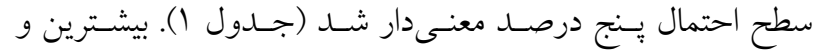
كمترين وزن خشك ريشـه در شـرايط غلظـت معمـول دىاكسـيد

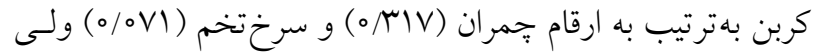

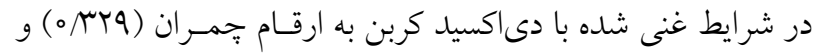

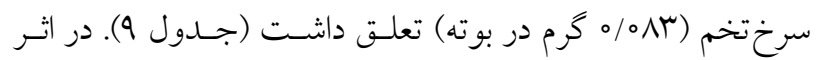
افزايش غلظـت دىاكسـيد كـربن وزن خشــ ريشـه كليـه ارقـام افزايش يافت. بيشترين و كمترين افزايش برابر Y Y/9 و N ا درصـد، بهترتيب به ارقام مرودشت و الموت تعلق داشت.
تأثير برهمكنش دىاكسيد كربن و رقم بر وزن خشك انــام

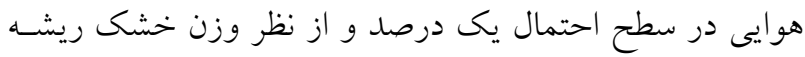

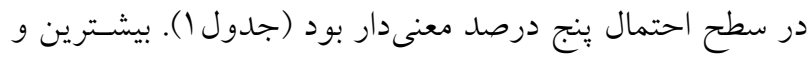
كمترين وزن خشـك انــام هـوايى در شـر ايط غلظـت معمـول دى اكسيد كربن بهترتيـب بـه ارقـام سـياهان (o/VNY) و شـيراز

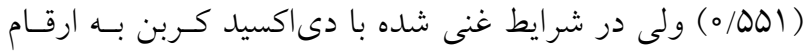

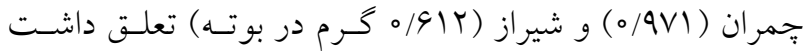
(جدول 9). بيشترين و كمتـرين وزن خشـى ريشـه در شـرايط غلظـت معمـول دىاكسـيد كـربن بـهـترتيـب بـهـ ارقـام جمهـران

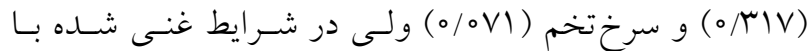

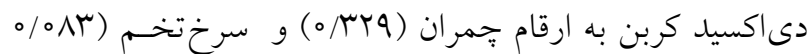
كرم در بوته) تعلق داشت. در اثر افزايش غلظت دئ دى اكسيد كربن

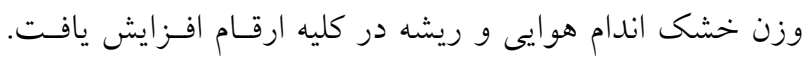




$$
\begin{aligned}
& \text { مرودشت، بين ها تاهب درصد و در ارقـام جّمـران، كـرج و تجـن } \\
& \text { بيش از م r درصد بود. ميزان كـاهش توليـد مـاده خشـك ناشسى از }
\end{aligned}
$$

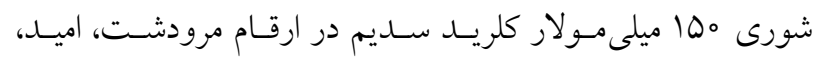

$$
\begin{aligned}
& \text { كاسيارود، شهريار، خشكى ال، تجن، كوير، قدس، جّمـران، نويـد، }
\end{aligned}
$$

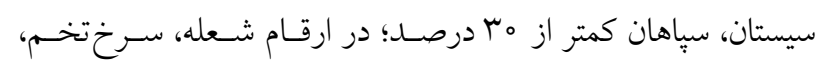

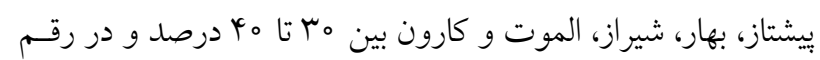

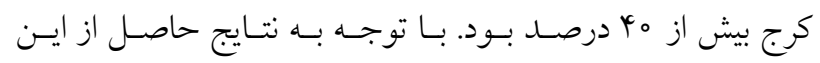

$$
\begin{aligned}
& \text { آزمايش، از بين ارقام مطالعه شده، در شرايط غير شور، رقم كـرج و }
\end{aligned}
$$

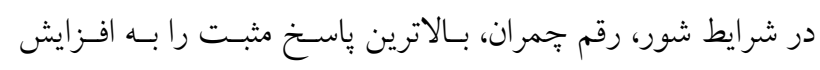

$$
\begin{aligned}
& \text { غلظت دىاكسيد كربن محيط نشان دادند. }
\end{aligned}
$$

$$
\begin{aligned}
& \text { نتيجه گيرى } \\
& \text { غنىشدهسازى غلظت دىاكسيد كربن محيط، تأثير مثتسى بـر توليـد } \\
& \text { ماده خشك ارقام كندم داشت و اندام هوايى در مقايسه با ريشـه بـهـ }
\end{aligned}
$$

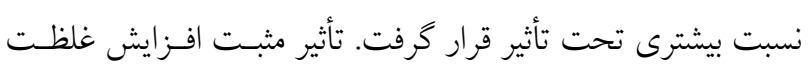

$$
\begin{aligned}
& \text { دىاكسيد كربن بر وزن خشك گيـاه در شـرايط شـور بيشـتر بـود. } \\
& \text { افزايش توليد ماده خشك در شرايط غنسى شـده غلظـت دىاكسـيد } \\
& \text { كربن، بهواسطه بهبود تعادل يونى و صفات مرتبط با رشد گياه بـود. }
\end{aligned}
$$

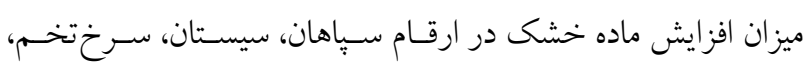

$$
\begin{aligned}
& \text { شيراز، كوير، الموت، خشكى |ل، شهريار، كـارون و اميــ كمتـر از } \\
& \text { ها درصد؛ در ارقام نويد، شعله، يِشتاز، بهـار، قــدس، كاسـيارود و }
\end{aligned}
$$

\section{منابع مورد استفاده}

1. Ackerly, D. D., J. S. Coleman, S. R. Morse and F. A. Bazzaz. 1992. $\mathrm{CO}_{2}$ and temperature effects on leaf-area production in two annual plant species. Ecology 73: 1260-1269.

2. Akbari Ghogdi, E., A. Izadi-Darbandi, A. Borzouei and A. Majdabadi. 2011. Evaluation of morphological changes in some wheat genotypes under salt stress. Journal of Science and Technology of Greenhouse Culture 1: 71-83.

3. Amirjani, M. R. 2011. Effect of salinity stress on growth, sugar content, pigments and enzyme activity of rice. International Journal of Botany 7: 73-81.

4. Arzani, A. and M. Salehi. 2012. Antioxidant activity and oxidative stress due to salinity in triticale and wheat lines in field condition. Journal of Plant Process and Function 1: 39-50.

5. Bourgault, M., M. F. Dreccer, A. T. James and S. C. Chapman. 2013. Genotypic variability in the response to elevated $\mathrm{CO}_{2}$ of wheat lines differing in adaptive traits. Functional Plant Biology 40: 172-184.

6. Bybordi, A., S. J. Tabatabaei and A. Ahmadi. 2010. Effect of salinity on the growth and peroxidase and IAA oxidase activities in canola. Journal of Food, Agriculture and Environment 8: 109-112.

7. Carden, D. E., D. J. Wakker, T. J. Flowers and A. J. Miller. 2003. Single cell measurement of the contribution of cytosolic $\mathrm{Na}^{+}$and $\mathrm{K}^{+}$to salt tolerance. Plant Physiology 131: 676-685.

8. Cheng, W., H. Sakai., K. Yagi and T. Hasegawa. 2009. Interactions of elevated $\left[\mathrm{CO}_{2}\right]$ and night temperature on rice growth and yield. Agricultural and Forest Meteoroloy 149: 51-58.

9. Cotrufo, M. F., P. Ineson and A. Scott. 1998. Elevated $\mathrm{CO}_{2}$ reduces the nitrogen concentration of plant tissues. Global Change Biology 4: 43-54.

10. Cousins, A. B., N. R. Adam, G. W. Wall, B. A. Kimball, P. J. Pinter Jr, M. J. Ottman, S. W. Leavitt and A. N. Webber. 2003. Development of $\mathrm{C} 4$ photosynthesis in sorghum leaves grown under free-air $\mathrm{CO}_{2}$ enrichment (FACE). Journal of Experimental Botany 54: 1969-1975.

11. El -Hendawy, S. E. 2004. Salinity tolerance in Egyptian spring wheat genotypes. PhD. Thesis. Department für pflanzenwissenschaften technische universität münchen.

12. Esfandiari, E., E. Javadi and M. Shokrpoor. 2013. Evaluation of some of biochemical and physiological traits in wheat cultivars in response to salinity stress at seedling stage. Journal of Crops Improvement 15: 27-38.

13. Farhoudi, R. 2014. Investigation the salinity tension effect on growth and physiological characteristics of nine wheat cultivars at vegetative growth stage. Crop Physiology Journal 5: 71-86. (In Farsi).

14. Flexas, J., J. Bota, F. Loreto, G. Cornic and T. D. Sharkey. 2004. Diffusive and metabolic limitations to photosynthesis under drought and salinity in C3 plants. Plant Biology 6: 269-279.

15. Georgios, A. and P. Christodoulides. 2009. Global warming and carbon dioxide through sciences. Environment International 35: 390-401.

16. Goufo, P., J. Pereira, J. Moutinho-Pereira, C. M. Correia, N. Figueiredo, C. Carranca, E. A. S. Rosa and H. Trindade. 2013. Rice (Oryza sativa L.) phenolic compounds under elevated carbon dioxide $\left(\mathrm{CO}_{2}\right)$ concentration. Environmental and Experimental Botany 99: 28-37.

17. Gurmani, A. R., S. U. Khan, F. Mabood, Z. Ahmed, S. J. Butt, J. Din, A. Mujeeb-Kazi and D. Smith. 2014. 
Screening and selection of synthetic hexaploid wheat germplasm for salinity tolerance based on physiological and biochemical characters. International Journal of Agriculture and Biology 16: 681-690.

18. Hogy, P., H. Wieser, P. Kohler, K. Schwadorf, J. Breuer, J. Franzaring, R. Muntifering and A. fangmeier. 2009. Effects of elevated $\mathrm{CO}_{2}$ on grain yield and quality of wheat: results from a 3-year free-air $\mathrm{CO}_{2}$ enrichment experiment. Plant Biology 60-69.

19. Kafi, M., M. Salehi and H. R. Eshghizadeh. 2010. Biosaline Agriculture: Plant, Water and Soil Management Approaches. Ferdowsi University of Mashhad, Iran, (In Farsi).

20. Kazemi, S. 2014. The response of rice (Oryza sativa L.) genotypes to increased sodium chloride concentration in nutrient solution under ambient and enriched air $\mathrm{CO}_{2}$. MSc. Thesis. Isfahan University of Technology. Isfahan, Iran.

21. Lawlor, D. W. and R. A. C. Mitchell. 2000. Crop ecosystem responses to climatic change: wheat. pp: 57-80. In: K. R. Reddy and H. F. Hodges (Eds.) Climate Change and Global Crop Productivity. CABI Publishing, Wallingford.

22. Lichtenthaler, H. K. and W. R. Welburn. 1994. Determination of total carotenoids and chlorophyls a and b of leaf extracts in different solvents. Biochemical Society Transactions 11: 591-592.

23. Mirmohammady Maibody, S. A. M and B. Ghareyazie. 2003. Physiological Aspects and Breeding for Salinity Stress in Plants. Isfahan University of Technology. Isfahan, Iran, (In Farsi).

24. Nicolas, M. E., R. Munns, A. B. Samarakoon and R. M. Gifford. 1993. Elevated $\mathrm{CO}_{2}$ improves the growth of wheat under salinity. Functional Plant Biology 20: 349-360.

25. North, G. R., K. Y. Kim, S. P. Shen and J. W. Hardin. 1995. Detection of forced climate signals. Part 1: Filter theory. Journal of Climate 6: 401-408.

26. O'Leary, G., B. Christy, J. Nuttall and N. Huth. 2015. Response of wheat growth, grain yield and water use to elevated $\mathrm{CO}_{2}$ under a Free-Air $\mathrm{CO}_{2}$ Enrichment (FACE) experiment and modelling in a semi-arid environment. Global Change Biology 21: 2670-2686.

27. Omidi Nargesi, S. 2014. Effects of nano-iron chelate on the response of wheat genotypes to salt stress. MSc. Thesis. Isfahan University of Technology. Isfahan, Iran.

28. Perez-Lopez, U., A. Robredo, M. Lacuesta and C. Sgherri. 2009. The oxidative stress caused by salinity in two barley cultivars is mitigated by elevated $\mathrm{CO}_{2}$. Physiolgia Plantarum 135: 29-42.

29. Poustini, K. and A. Siosemardeh. 2004. Ion distribution in wheat cultivars in response to salinity stress. Field Crops Research 55: 125-133.

30. Qaderi, M. M., L. V. Kurepin and D. M. Reid. 2006. Growth and physiological responses of canola (Brassica napus) to three components of global climate change: temperature, carbon dioxide and drought. Physiolgia Plantarum 128: 710-721.

31. Rios- Gonzalez, K., L. Erdei and S. H. Lips. 2002. The activity of antioxidant enzymes in maize and sunflower seedlings as affected by salinity and different nitrogen sources. Plant Science 162: 923-930.

32. Rogers, H. H., G. B. Runion, S. A. Prior, A. J. Price and H. A. Torbert. 2008. Effects of elevated atmospheric $\mathrm{CO}_{2}$ on invasive plants: comparison of purple and yellow nutsedge (Cyperus rotundus L. and C. esculentus L.). Journal of Environmental Qualilty 37: 395-400.

33. Shoor, M., M. Goldani and F. Mondani. 2010. Effect of $\mathrm{CO}_{2}$ enrichment on morphophysiological traits in Tagets spp, Ageratum spp and Gauilardia spp in greenhouse condition. Journal of Agroecology 1: 101-108 .

34. Tabatabaei, S. and P. Ehsanzadeh. 2015. Photosynthetic pigments, ionic and antioxidative behaviour of hulled tetraploid wheat in response to $\mathrm{NaCl}$. Photosynthetica 54: 1-19.

35.Zehtab, S. 2015. Response of barley (Hordeum Vulgare L.) genotypes to salt stress under elevated $\mathrm{CO}_{2}$ concentration and temperature. MSc. Thesis. Isfahan University of Technology. Isfahan, Iran.

36. Zhao, G. Q., B. L. Ma and C. Z. Ren. 2007. Growth, gas exchange, chlorophyll fluorescence and ion content of Nakota oat in response to salinity. Crop Science 47: 123-131.

37.Ziska, L. H., J. R. Teasdale and J. A. Bunce. 1999. Future atmospheric carbon dioxide may increase tolerance to glyphosate. Weed Science 47: 608-615. 


\title{
The Response of Wheat Cultivars to the Elevated Concentration of Air Carbon Dioxide and Salinity
}

\author{
M. Saleh ${ }^{1}$, M. Zahedi ${ }^{*}$ and H. Eshgizadeh ${ }^{3}$
}

(Received: May 22-2017; Accepted: January 27-2018)

\begin{abstract}
This experiment was conducted in a greenhouse at Isfahan University of Technology, Isfahan, Iran in 2014 to evaluate 20 wheat cultivars (Navid, Pishtaz, Karaj, Kavir, Tajan, Karun, sholeh, Bahar, Khoshki 11, Gasparood, Sepahan, Sorkh tokhm, Chamran, Ghods, Shariar, Omid, Sistan, Alamut, Marvdasht and Shiraz) under two carbon dioxide concentrations (the ambient 360 and the enriched $700 \mu \mathrm{M})$ and two salinity levels $(0$ and $150 \mathrm{mM} \mathrm{NaCl})$. Treatments were arranged as a factorial in a completely random design with three replications. The results showed that salinity decreased potassium concentration in shoots $(27 \%)$ and roots $(39 \%)$, chlorophyll a and b concentrations $(27$ and $30 \%$, respectively), carotenoids concentration (21\%), plant height (39\%), leaf area (32\%), root volume (40\%), shoot and root dry weight (30\% and $23 \%$, respectively); however, it increased sodium concentration in the shoots and roots $(36 \%)$. The extent of salt-induced decreases in the shoot dry weight of the evaluated cultivars ranged from 8 to $46 \%$. Karaj and Marvdasht cultivars were the most and the least sensitive cultivars to salinity under both ambient and enriched carbon dioxide concentrations, respectively. The elevated carbon dioxide concentration increased potassium concentration in the shoots (except Sholeh, Ghods and Gasparood) and roots, chlorophyll and carotenoids concentrations, plant height, leaf area (except Shahriar), root volume, shoot (except Sistan and Omid), and root dry weight; however, it decreased sodium concentration in the shoots and roots. The highest and the lowest increases in the shoot dry weight under non saline condition were obtained for Karaj and Alamut (23 and 6\%, respectively); under saline conditions, they were found in Chamran and Kavir (66 and 3\%, respectively). The results obtained from this experiment showed that the elevated carbon dioxide concentration positively influenced the growth of most cultivars. This effect was more pronounced under saline conditions, indicating that carbon dioxide enrichment could alleviate, at least in part, the negative effects of salinity.
\end{abstract}

Keywords: Climate change, Wheat cultivars, Salinity, Air carbon dioxide concentration

1, 2, 3. MSc. Graduate, Associate Professor and Assistant Professor, Respectively, Department of Agronomy and Plant Breeding, College of Agriculture, Isfahan University of Technology, Isfahan, Iran.

*: Corresponding Author, Email: mzahedi@cc.iut.ac.ir 